\title{
Flavonoids from Uvaria alba attenuate LPS-induced inflammatory responses by suppressing NF- $\kappa B$ activation in RAW 264.7 macrophages: In silico and in vitro perspectives
}

Kin Israel R. Notarte ${ }^{1,2}$, Mark Tristan J. Quimque ${ }^{1,3}$, Imee T. Macaranas ${ }^{2}$, Abbas Khan ${ }^{4}$, Adriel M. Pastrana ${ }^{2}$, Oliver B. Villaflores ${ }^{5}$, Hans Christian P. Arturo ${ }^{1}$, Delfin Yñigo H. Pilapil IV ${ }^{1}$, Sophia Morgan M. Tan ${ }^{1}$, Dong-Qing Wei ${ }^{4}$, Arlette Wenzel-Storjohann ${ }^{6}$, Deniz Tasdemir ${ }^{6}$, Yung Hyun Choi $^{7^{*}}$ and Allan Patrick G. Macabeo ${ }^{1^{*}}$

${ }^{1}$ Laboratory of Organic Reactivity, Discovery \& Synthesis, Research Center for Natural \& Applied Sciences, University of Santo Tomas, 1015 España, Manila, Philippines

${ }^{2}$ Faculty of Medicine \& Surgery, University of Santo Tomas, 1015 España, Manila, Philippines

${ }^{3}$ Chemistry Department, College of Science and Mathematics, Mindanao State University - Iligan Institute of Technology, Tibanga, 9200 Iligan City, Philippines

${ }^{4}$ Department of Bioinformatics and Biostatistics, State Key Laboratory of Microbial Metabolism, Shanghai Jiao Tong University, 800 Dongchuan Road Shanghai, Minhang District, China, 200240

${ }^{5}$ Laboratory of Phytochemistry, Research Center for Natural \& Applied Sciences, University of Santo Tomas, 1015 España, Manila, Philippines

${ }^{6}$ Marine Natural Products Chemistry Research Unit, GEOMAR Helmholtz Centre for Marine Biotechnology (GEOMAR-Biotech), Am Kiel-Kanal 44, Kiel 24106, Germany

${ }^{7}$ Department of Biochemistry, Dongeui University College of Korean Medicine, 52-57, Yangjeong-ro, Busanjin-gu Busan 47227, Republic of Korea

*Corresponding authors:

\section{Prof. Allan Patrick Macabeo, PhD}

Laboratory of Organic Reactivity, Discovery \& Synthesis (LORDS)

Research Center for Natural \& Applied Sciences, University of Santo Tomas, 1015 Manila, Philippines

Email: agmacabeo@ust.edu.ph

\section{Prof. Yung Hyun Choi, PhD}

Department of Biochemistry Dongeui University College of Korean Medicine 52-57, Yangjeong-ro, Busanjin-gu Busan 47227, Republic of Korea Email: choiyh@deu.ac.kr 


\begin{abstract}
Background: Hyperreactive inflammatory response occurs when there is excessive activation of $\mathrm{NF}-\kappa \mathrm{B}$ leading to a pathologic cascade of inflammatory reactions.

Purpose: The Philippine medicinal endemic plant Uvaria alba was investigated for its inflammatory modulating potentials. Thus, the anti-inflammatory effects of putative flavonoids from $U$. alba butanol sub-extract (UaB) were explored by targeting NF- $\mathrm{B}$ activation and expression of proinflammatory mediators and cytokines.
\end{abstract}

Study Design: LPS-challenged RAW 264.7 macrophages were used as experimental model for evaluating inflammatory modulating effects of $U$. alba.

Methods: ELISA was initially performed to measure levels of proinflammatory mediators (NO and $\mathrm{PGE}_{2}$ ) and cytokines (TNF- $\alpha$, IL-1 $\beta$ and IL-6), followed by RT-PCR and western blotting to determine mRNA and protein expression, respectively. Using immunofluorescence staining

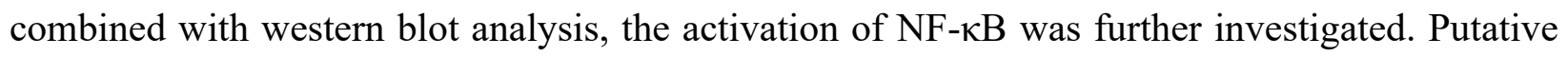
flavonoids from $\mathrm{UaB}$ were identified using high resolution LC-MS and subjected to in silico screening against COX-1/2, iNOS, TNF- $\alpha$, TACE, and IKK via molecular docking and molecular dynamics simulations at $140 \mathrm{~ns}$.

Results: UaB abrogated protein and mRNA expressions of iNOS, COX-2, TNF- $\alpha$, IL-1 $\beta$ and IL6 by suppressing the production of proinflammatory mediators and cytokines. Furthermore, UaB potentially attenuated NF- $\mathrm{B}$ activation by inhibiting the nuclear translocation of the transcription factor p65. LC-MS analysis with $\mathrm{UaB}$ revealed the presence of flavonol aglycones - quercetin (4) and kaempferol (6) - and their glycosylated derivatives - quercitrin (3), rutin (5), and kaempferol 3-O-rutinoside (7). Molecular docking analysis suggests that the major flavonol aglycones exhibited high affinity towards COX-2 NSAID-binding site, TNF- $\alpha$ and TACE, while 
the glycosylated flavonoids showed high affinity towards iNOS and IKK. The top protein-ligand complexes were found to be dynamically stable as shown by molecular dynamics simulations.

Conclusion: This is the first report highlighting the mechanistic in silico and in vitro antiinflammatory potential of $U$. alba.

Keywords: proinflammatory mediators, cytokines, RT-PCR, western blot, ELISA, LC-MS, molecular docking, molecular dynamics, pharmacokinetics 


\section{Introduction}

Inflammation is a physiologic response of the body to eliminate unwanted antigens and prevent further tissue damage (Hung and Suzuki, 2017). However, insufficient or excessive inflammatory response can be pathologic (Biswas and Bagchi, 2016; Fujiwara and Kobayashi, 2005; Hung and Suzuki, 2017). In a bacteria-induced infection, inflammation is mediated by lipopolysaccharide (LPS) that acts as an antigen triggering the immune system to activate macrophages and lymphocytes to produce proinflammatory mediators (prostaglandins and nitric oxide) and cytokines (TNF-a, IL-1, IL-2, IL-6, IL-8 and IL-12) (Fujiwara and Kobayashi, 2005; Hung and Suzuki, 2017; Liu et al., 2017). At the molecular level, these processes are regulated by the proinflammatory molecule NF- $\kappa \mathrm{B}$ which can either be a homodimer or heterodimer with $\mathrm{p} 50$, p52 or p65 subunits. The NF- $\mathrm{B}$ pathway is of interest because of its role in chronic diseases, including rheumatoid arthritis, atherosclerosis, cancer, and neurodegenerative diseases (Biswas

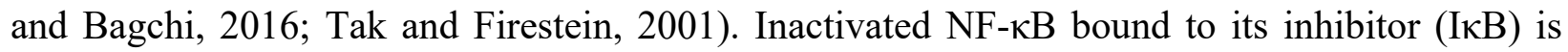
found in the cytoplasm. For nuclear translocation of NF- $\kappa \mathrm{B}$ to occur, phosphorylation of I $\mathrm{B}$ is required which is initiated by $\mathrm{I} \kappa \mathrm{B}$ kinase $(\mathrm{IKK})$ in the presence of an inflammatory stimulus. Upon activation, there is expression of $\mathrm{NF}-\mathrm{\kappa B}$ proteins which serves as transcription factor for inflammatory genes initiating the cascade of inflammatory reactions (Liu et al., 2017; Tak and Firestein, 2001). Thus, efforts to target the NF- $\kappa B$ pathway is an appealing strategy to modulate inflammatory response using natural products or synthetic compounds (Yamamoto and Gaynor, 2005).

The World Health Organization (2009) reported that $80 \%$ of the world's population depends exclusively on plants for their health and healing, hence the discovery and development of pharmacologically active plant metabolites is of great importance. Of particular interest is the 
genus Uvaria, a member of the Annonaceae family recognized for its biologically active natural products with antimicrobial, antioxidant, and cytotoxic properties. Of the 20 species of Uvaria recognized in the Philippines, only four species have been studied for their pharmacologic potential (Macabeo et al., 2010, 2012, 2014, 2017; Notarte et al., 2019; Quimque et al., 2021b; Tudla et al., 2007). Uvaria alba Merr., an endemic shrub widely distributed in the Bataan and Zambales provinces of Luzon, was found to produce cytostatic and antitubercular secocyclohexenes, albanols A and B, along with the oxepinone metabolite grandiuvarone (Macabeo et al., 2017). In a follow-up study, the dichloromethane sub-extract of $U$. alba was also reported to contain phosphodiesterase and acetylcholinesterase inhibitors implicating its potential anticancer and anti-Alzheimer's disease-targeting properties (Quimque et al., 2021b). To date, there has been no scientific study exploring the inflammatory modulating properties of $U$. alba. Recognizing the association of inflammatory processes with a myriad of diseases, it is of our best interest to explore the anti-inflammatory potentials of flavonoids from $U$. alba butanol sub-extract (UaB) by targeting NF- $\mathrm{kB}$ activation and its associated proinflammatory mediators and cytokines.

\section{Materials and methods}

\section{Plant collection and identification}

The leaves of $U$. alba were collected in the lowlands of Palauig, Zambales, Luzon, Philippines (15 $\left.43^{\prime} \mathrm{N}, 119^{\circ} 91^{\prime} \mathrm{E}\right)$ in May 2020. These were authenticated with voucher specimens (USTH 1631) deposited at the University of Santo Tomas Herbarium and at the Philippine National Herbarium, Manila, Philippines. 


\section{Crude extraction and fractionation}

The ground air-dried leaves $(2.1 \mathrm{~kg})$ were extracted with technical-grade $(1: 1)$ DCM$\mathrm{MeOH}$ and concentrated in vacuo at $45^{\circ} \mathrm{C} .349 \mathrm{~g}$ of crude DCM-MeOH extract (Ua) was yielded. Ua crude extract was suspended in distilled water and partitioned according to increasing polarity, yielding three sub-extracts, namely, petroleum ether (UaP), DCM (UaD), and $n$-butanol (UaB) sub-extracts. The sub-extracts were concentrated in vacuo and tested for biological activities.

\section{Cell viability assay}

U. alba samples were assayed for cytotoxicity against human keratinocytes (HaCaT) and human liver cancer cells (HepG2) using the CellTiter-Blue ${ }^{\circledR}$ Cell Viability Assay (Promega, Mannheim, Germany). Both HaCaT and HepG2 were maintained in RPMI 1640 medium (Life Technologies, Darmstadt, Germany) supplemented with $10 \%$ fetal bovine serum (Life Technologies, Darmstadt, Germany), $100 \mathrm{U} / \mathrm{mL}$ penicillin, and $100 \mathrm{mg} / \mathrm{mL}$ streptomycin (Promocell, Heidelberg, Germany). Cultures were incubated at $37^{\circ} \mathrm{C}$ under a humidified atmosphere and 5\% $\mathrm{CO}_{2}$. The cell lines were subcultured every 3-4 days.

Cells were seeded in 96-well plates at concentration of $1 \times 10^{4}$ cells/well. After $24 \mathrm{~h}$ incubation, the medium was removed, and the test samples were added to the cells. The reference chemotherapeutic drug was doxorubicin. Following the addition of the samples, the plates were cultured for $24 \mathrm{~h}$ at $37^{\circ} \mathrm{C}$. Hereafter, $20 \mu \mathrm{L}$ of the CellTiter-Blue ${ }^{\circledR}$ reagent was dispensed to each well and the cells were further incubated for $2 \mathrm{~h}$ at $37^{\circ} \mathrm{C}$. Fluorescence was measured using the microplate reader Infinite M200 (Tecan Trading AG, Switzerland) at excitation of $560 \mathrm{~nm}$ and emission of $590 \mathrm{~nm}$. IC 50 was computed in GraphPad PRISM 5 software (GraphPad Software Inc.). 


\section{ELISA-based cyclooxygenase inhibition assay}

The anti-inflammatory property of $U$. alba was evaluated based on its inhibition of COX1 and COX-2 isoenzymes. Following the manufacturer's protocol (cat. nos. 701070 and 701080; Cayman Chemical Co., Ann Arbor, MI, USA), an Enzyme-Linked Immunosorbent Assay (ELISA) was performed with minor modifications (Garcia et al., 2021). U. alba samples were dissolved in DMSO and the 96-well plates were read using Glomax microplate reader (Promega, Madison, Wisconsin) at $450 \mathrm{~nm}$. IC 50 was calculated in GraphPad PRISM 5 software (GraphPad Software Inc., CA, USA). Selectivity index of the samples against COX-1 and COX-2 was determined using the formula: $\mathrm{IC}_{50} \mathrm{COX}-1 / \mathrm{IC}_{50} \mathrm{COX}-2$ (Duggan et al., 2010).

\section{Macrophage culture and LPS stimulation}

U. alba butanol sub-extract $(\mathrm{UaB})$ having a selective $\mathrm{COX}-2$ inhibitory activity was further tested for its anti-inflammatory properties on LPS-challenged murine macrophages. RAW 264.7 cell line was maintained in DMEM containing 10\% fetal bovine serum, $2 \mathrm{mM}$ L-glutamine, 100 U/mL penicillin, and $100 \mathrm{U} / \mathrm{mL}$ streptomycin (WelGENE Inc., Daegu, Korea). Cell cultures were incubated at $37^{\circ} \mathrm{C}$ in a humidified atmosphere containing $5 \% \mathrm{CO}_{2}$ and $95 \%$ air.

$\mathrm{UaB}$ sub-extract was dissolved in DMSO and final concentrations were adjusted by dilution with complete culture medium. To stimulate the cells, the medium was replaced with fresh DMEM. LPS (E. coli Serotype 055:B5; cat. no. L2880; Sigma-Aldrich, Merck KGaA) was added in the presence or absence of the UaB sub-extract for the indicated periods. 


\section{Assessment of macrophage viability}

To evaluate cytotoxicity of the UaB sub-extract on murine macrophages, RAW 264.7 cells were seeded in 96-well plates at a density of $1 \times 10^{3}$ cells/well. Cells were treated with various concentrations of the $\mathrm{UaB}$ sub-extract for $1 \mathrm{~h}$ prior to incubation with $100 \mathrm{ng} / \mathrm{mL}$ LPS for $24 \mathrm{~h}$. Subsequently, MTT (Sigma-Aldrich, Merck KGaA) was added to each well at $0.5 \mathrm{mg} / \mathrm{mL}$, followed by incubation for $3 \mathrm{~h}$ at $37^{\circ} \mathrm{C}$ in the dark. MTT solution was removed and $200 \mu \mathrm{L} 5 \%$ DMSO was added to dissolve the crystals. The viable cells were detected by reading the absorbance of formazan at $540 \mathrm{~nm}$ using an ELISA microplate reader (Dynatech Laboratories, Chantilly, VA, USA). The optical density of formazan formed in the untreated cells was considered to represent $100 \%$ viability.

\section{Measurement of NO and PGE2 production}

RAW 264.7 cells were pretreated with UaB sub-extract for $1 \mathrm{~h}$; subsequently, they were stimulated with LPS for $24 \mathrm{~h}$. Controls were maintained under the same culture conditions; however, they were not pre-incubated or stimulated. NO levels were indirectly determined by measuring the stable NO catabolite nitrite in the medium utilizing the Griess reaction. In brief, the conditioned medium $(100 \mu \mathrm{L})$ was mixed with the same volume of Griess reagent (Sigma-Aldrich, Merck KGaA) and incubated for $10 \mathrm{~min}$ at room temperature. The optical density at $540 \mathrm{~nm}$ was measured using an ELISA microplate reader and the nitrite concentration was calculated according to a standard curve generated from known concentrations of sodium nitrite. The PGE2 concentration in the conditioned medium was measured using a commercial PGE2 ELISA kit (cat. no. 514010; Cayman Chemical Co., Ann Arbor, MI, USA) following the manufacturer's instructions. 


\section{ELISA for proinflammatory cytokines}

The generation of proinflammatory cytokines TNF- $\alpha$, IL-1 $\beta$, and IL- 6 was measured using ELISA kits. The RAW 264.7 cells were pre-incubated with the UaB sub-extract for $1 \mathrm{~h}$, followed by LPS stimulation for $24 \mathrm{~h}$, and cytokine contents in the cell-free supernatants were measured using cytokine sandwich ELISA kits (cat. nos. MTA00B and MLB00C; R\&D Systems, Minneapolis, MN, USA) according to the manufacturer's protocols.

\section{Reverse transcription-polymerase chain reaction (RT-PCR) assay}

The RAW 264.7 cells were pretreated with UaB sub-extract for $1 \mathrm{~h}$, followed by treatment with $100 \mathrm{ng} / \mathrm{mL}$ LPS for $24 \mathrm{~h}$. Controls were maintained under the same culture conditions, but were not pre-incubated or stimulated. Total RNA was extracted using TRIzol reagent (Invitrogen, Thermo Fisher Scientific Inc., Waltham, MA, USA), according to the manufacturer's instructions. The complementary (c)DNA of each sample was prepared using $2 \mu \mathrm{g}$ RNA, $1 \mu \mathrm{L}$ Moloney's murine leukemia virus reverse transcriptase, $1 \mathrm{mM}$ deoxynucleoside triphosphate, and $1 \mu \mathrm{L}$ oligo(dT) according to the manufacturer's protocol. DNA amplification was performed in AccuPower ${ }^{\circledR}$ PCR PreMix (Bioneer Corp., Daejeon, Korea). iNOS, COX-2, TNF- $\alpha$, IL-1 $\beta$, and IL-6 genes were amplified from the cDNA using PCR (Eppendorf, Hamburg, Germany). After amplification, the PCR products were electrophoresed on 1\% agarose gels and visualized following staining with ethidium bromide (Sigma-Aldrich, Merck KGaA) for 10 min at room temperature under ultraviolet irradiation using the Gel Documentation System (CHEMI-SMART 2026M.WL, Vilber Lourmat, Marne-la-Valle, France). Glyceraldehyde-3-phosphate dehydrogenase (GAPDH) was used as a loading control. The PCR primers were as follows: iNOS forward, 5'-ATG TCC GAA GCA AAC ATCAC-3' and reverse, 5'-TAA TGT CCA GGA AGT 
AGG TG-3'; COX-2 forward, 5'-CAG CAA ATC CTT GCT GTT CC-3' and reverse, 5'-TGG GCA AAG AAT GCA AAC ATC-3'; TNF- $\alpha$ forward, 5'-TCT CAT CAG TTC TAT GGC CC-3' and reverse, 5'-GGG AGT AGA CAA GGT ACA AC-3'; IL-1 $\beta$ forward, 5'-GGG CTG CTT CCA AAC CTT TG-3' and reverse, 5'-GCT TGG GAT CCA CAC TCT CC-3', IL-6 forward, 5'-AAG TGC ATC ATC GTT GTT TTCA-3' and reverse, 5'-GAG GAT ACC ACT CCC AAC AG-3'; and GAPDH forward, 5'-AGG CCG GTG CTG AGT ATG TC-3' and reverse, 5'-TGC CTG CTT CAC CAC CTT CT-3' (Bioneer Corp.). The PCR reaction was initiated at $94^{\circ} \mathrm{C}$ for $2 \mathrm{~min}$, followed by 25 cycles of $94^{\circ} \mathrm{C}$ for $30 \mathrm{sec}$, annealing temperature for $30 \mathrm{sec}$ and $72^{\circ} \mathrm{C}$ for $30 \mathrm{sec}$, and a final extension step at $72^{\circ} \mathrm{C}$ for $5 \mathrm{~min}$. The annealing temperatures were $63^{\circ} \mathrm{C}$ for iNOS, COX-2, TNF$\alpha, \mathrm{IL}-1 \beta$ and IL-6, and $61^{\circ} \mathrm{C}$ for GAPDH.

\section{Protein isolation and western blot analysis}

RAW 264.7 cells were incubated with the UaB sub-extract at the indicated concentrations for $1 \mathrm{~h}$ prior to stimulation with $100 \mathrm{ng} / \mathrm{mL}$ LPS for $24 \mathrm{~h}$. As described previously by Park et al., (2020), the cells were collected, lysed with a cell lysis buffer and the protein concentration was determined using the Bradford Protein assay kit (Bio-Rad Laboratories, Hercules, CA, USA). In a parallel experiment, cytoplasmic and nuclear extracts were prepared using an NE-PER Nuclear and Cytoplasmic Extraction reagents kit (Pierce, Thermo Fisher Scientific, Inc.) following the manufacturer's instructions. For western blotting, equal amounts of protein samples ( $30 \mu \mathrm{g} / \mathrm{lane})$ were subjected to $10-13 \%$ sodium dodecyl sulfate-polyacrylamide gel electrophoresis (SDSPAGE) and then electrophoretically transferred onto polyvinylidene difluoride membranes (Schleicher \& Schuell, Keene, NH, USA). Subsequently, the membranes were blocked with 5\% nonfat dry milk in Tris-buffered saline containing $0.1 \%$ Triton X-100 (TBST) for $1 \mathrm{~h}$ and probed 
with specific primary antibodies as previously described by (Kwon et al., 2018) at $4^{\circ} \mathrm{C}$ overnight. After washing with TBST, the membranes were incubated with the appropriate horseradish peroxidase (HRP)-conjugated secondary antibodies (dilution, 1:500; cat. no. sc-2004, goat antirabbit IgG-HRP; sc-2005, goat anti-mouse IgG-HRP; Santa Cruz Biotechnology, Inc., Santa Cruz, CA, USA) for $2 \mathrm{~h}$ at room temperature. The protein bands were detected on X-ray film using an enhanced chemiluminescence kit (cat. no. RPN 2232; GE Healthcare Life Sciences, Little Chalfont, UK) following the manufacturer's instructions.

\section{Immunofluorescence staining}

The effect of UaB on LPS-induced nuclear translocation of NF-kB was assessed using immunofluorescence microscopy. The RAW 264.7 cells were initially grown on glass coverslips for $24 \mathrm{~h}$ at $37^{\circ} \mathrm{C}$ in a humidified atmosphere containing $5 \% \mathrm{CO}_{2}$ and subsequently incubated with $80 \mathrm{ng} / \mathrm{mL} \mathrm{UaB}$ for $1 \mathrm{~h}$ prior to treatment with $100 \mathrm{ng} / \mathrm{mL}$ LPS for $30 \mathrm{~min}$ in the same culture conditions. The cells were fixed in 3.7\% paraformaldehyde for $15 \mathrm{~min}$, permeabilized with $0.2 \%$ Triton X-100 in phosphate-buffered saline (PBS) for $15 \mathrm{~min}$ and blocked for $10 \mathrm{~min}$ at room temperature with PBS containing 5\% bovine serum albumin (Sigma-Aldrich, Merck KGaA). The cells were then stained with the primary antibody against NF-kB p65 (1:100 dilution) overnight at $4^{\circ} \mathrm{C}$. Subsequently, cells were incubated with a fluorescein-conjugated anti-rat immunoglobulin $\mathrm{G}$ (1:100 dilution; cat. no. 31629; Molecular Probes, Thermo Fisher Scientific, Inc.) in the dark for $40 \mathrm{~min}$ at $37^{\circ} \mathrm{C}$. Nuclei were sequentially stained with $2.5 \mu \mathrm{g} / \mathrm{mL}$ DAPI solution (Sigma-Aldrich, Merck KGaA). The slides were then mounted and fluorescence images were captured using a fluorescence microscope (Carl Zeiss, Oberkochen, Germany). 


\section{Statistical analyses}

Each in vitro experiment was performed in triplicate and values are expressed as the mean \pm standard deviation. Statistical analysis was performed using GraphPad PRISM 5 software (GraphPad Software Inc.). Differences between groups were assessed using analysis of variance followed by Tukey's post hoc test or unpaired Student's t-test. $P<0.05$ was deemed statistically significant.

\section{High resolution liquid chromatography - mass spectrometry}

$U$. alba butanol sub-extract (UaB), being the most biologically active, was chemically profiled for the identification of its putative secondary metabolites using LC-HR-ESIMS-QToF performed on a Shimadzu LC-20 AD apparatus equipped with an autosampler (SIL-20A, Shimadzu), diode array detector (SPD-M20AV, Shimadzu), and coupled with a microToF II (Bruker Daltonics) ESI-QToF mass spectrometer. HPLC column Chromolith Performance RP-18e $(2.0 \times 100 \mathrm{~mm}$ i.d. $)$ was used for the analysis. The eluents were acetonitrile and water with $0.1 \%$ acetic acid. After injecting $5 \mu \mathrm{L}$ of the UaB sub-extract, flow elution was set at $0.2 \mathrm{~mL} / \mathrm{min}$. The effluents were monitored at $350 \mathrm{~nm}$. The mass spectra were recorded in the mass range $m / z 50$ to 2000. The Bruker DataAnalysis 4.3 software (Bruker, Germany) was used for data acquisition and analysis. Individual components were identified by comparison of their $m / z$ values in the total ion count profile with those compounds described in literature or by matching their MS/MS spectra with those reported in a public repository of mass spectral data called MassBank.

\section{Molecular docking}

Molecular docking methodologies are used for predicting the binding behavior of ligands onto various receptors (Brogi et al., 2022; de Leon et al., 2021; Fernandez et al., 2021; Quimque 
et al., 2021a). In this study, all molecular docking experiments were performed on the UCSF Chimera platform (Pettersen et al., 2004). The three-dimensional structures of the proteins were retrieved from RCSB protein data bank (RCSB.org) added to the docking platform as PDB format. Each protein crystal structure was processed by removing existing co-crystallized ligands and water molecules. Meanwhile, the ligands were added to the docking platform, rendered from SMILES notation or added as a SYBYL mol2 file. Minimization and docking preparation of ligand and protein structures were done by adding the missing hydrogen atoms and appropriate charges to the structures employing the Gasteiger charge method computed using Amber's Antechamber module (Wang et al., 2006). The docking procedure was done using a flexible ligand into a flexible active site protocol, where the ligand was allowed to be flexible and torsion within a grid box encompassing the ligand-binding cavity of each enzyme. A grid box was set around the bound cocrystallized ligand of the enzyme. With all docking parameters maintained at default values, (number of binding modes $=10$ at maximum exhaustiveness search), molecular docking simulation was performed following the Broyden-Fletcher-Goldfarb-Shanoo algorithm of AutoDock Vina (version 1.1.2) (Trott and Olson, 2010). After each docking experiment, AutoDock Vina provides a set of docking poses for each ligand and corresponding binding affinities in which the docking pose with the best affinity was further subjected to postdock analysis. Visualization and analysis of the enzyme-ligand complex conformation were carried out using ChimeraX and Biovia Discovery Studios (version 4.1) (Quimque et al., 2021). Validation of the docking protocol was done by extracting the bound co-crystallized ligand and re-docking it to the set grid (Quimque et al., 2021; Santos et al., 2021). 


\section{Molecular dynamics simulation and binding free energy calculations}

Using the AMBER20 tool, the dynamics and binding of each ligand in their respective pockets was performed by employing FF19SB force field (Case et al., 2005; Pearlman et al., 1995; Salomon-Ferrer et al., 2013a). For solvation purposes an OPC water box module was used while sodium and chlorine ions were added for system neutralization. Using steepest descent and conjugate gradient algorithms gentle minimization was achieved (Meza, 2010; Watowich et al., 1988) followed by equilibration using both weak and without restraint and heating at $300 \mathrm{~K}$ and constant pressure. PMEMD.CUDA enabled simulation for 140ns each (Salomon-Ferrer et al., 2013b). The tCOLrajectories were processed using CPPTRAJ and PTRAJ modules (Roe and Cheatham, 2013).

Using MM/GBSA, the binding free energy for each complex was calculated which is used by large scale studies such as protein-protein, protein-ligand and protein-RNA/DNA interactions (Ali et al., 2020; Khan et al., 2020; Tahir Ul Qamar et al., 2021; Wang et al., 2019). To estimate the total binding energy such as electrostatic, generalized born (GB), surface accessible (SA) and van der Waals (vdW), the MMGBSA.py script was utilized (Sun et al., 2014). The following equation was used for energy calculation:

$$
\Delta G(\text { bind })=\Delta G(\text { complex })-[\Delta G(\text { receptor })+\Delta G(\text { ligand })]
$$

The above-mentioned component of the total free energy was calculated using the equation below:

$$
G=\text { Gbond }+ \text { Gele }+ \text { GvdW }+ \text { Gpol }+ \text { Gnpol }
$$




\section{Results}

\section{Screening for selective COX-2 inhibition}

The crude and sub-extracts of $U$. alba were tested for their potential in attenuating inflammation (Table 1). The plant samples were initially screened for inhibition of COX-2 using ELISA. Only the butanol sub-extract (UaB) showed enzymatic inhibition of COX-2 with an $\mathrm{IC}_{50}$ of $0.63 \mu \mathrm{g} / \mathrm{mL}$ which is comparable to the reference drug celecoxib $\left(\mathrm{IC}_{50}=0.34 \mu \mathrm{g} / \mathrm{mL}\right.$ ). To establish anti-COX-2 selectivity, $\mathrm{UaB}$ was further screened for inhibition of COX-1. Interestingly, UaB did not antagonize COX-1 with $\mathrm{IC}_{50}>100 \mu \mathrm{g} / \mathrm{mL}$. In terms of selectivity, $\mathrm{UaB}(\mathrm{SI}>158.73$ ) was more selective compared to celecoxib $(\mathrm{SI}=7.74)$.

\section{Screening for cytotoxicity against HaCaT and HepG2}

Aside from anti-COX screening, cytotoxicity assay on non-tumorigenic human keratinocytes (HaCaT) and liver cancer cells (HepG2) was performed (Table 1). Of the samples tested, the dichloromethane (UaD) sub-extract was slightly cytotoxic against $\mathrm{HepG} 2$ with $\mathrm{IC}_{50}$ of $79.7 \mu \mathrm{g} / \mathrm{mL}$. On the other hand, no extract was cytotoxic against HaCaT. UaB which showed a selective COX-2 inhibition was non-cytotoxic to both HaCaT and HepG2. 
Table 1. Cytotoxicity and enzymatic inhibition of cyclooxygenase by the crude and sub-extracts of $U$. alba.

\begin{tabular}{|c|c|c|c|c|c|}
\hline \multirow[t]{2}{*}{ Sample } & \multicolumn{2}{|c|}{$\begin{array}{l}\text { Cytotoxicity } \\
(\mu \mathrm{g} / \mathrm{mL})\end{array}$} & \multicolumn{3}{|c|}{ Anti-inflammatory property $(\mu \mathrm{g} / \mathrm{mL})$} \\
\hline & $\mathrm{HaCaT}$ & HepG2 & $\mathrm{COX}-2$ & $\mathrm{COX}-1$ & $\begin{array}{l}\text { Selectivity } \\
\text { Index (SI) }\end{array}$ \\
\hline $\mathrm{Ua}$ & $>100$ & $>100$ & $>100$ & NT & NT \\
\hline UaP & $>100$ & $>100$ & $>100$ & NT & NT \\
\hline $\mathrm{UaD}$ & $>100$ & $79.7 \pm 1.2$ & $>100$ & NT & NT \\
\hline $\mathrm{UaB}$ & $>100$ & $>100$ & $0.63 \pm 0.5$ & $>100$ & $>158.73$ \\
\hline $\begin{array}{l}+ \text { Control } \\
\text { Doxorubicin } \\
\text { Celecoxib }\end{array}$ & $\begin{array}{c}19.8 \pm 0.8 \\
\text { NT }\end{array}$ & $\begin{array}{c}11.4 \pm 0.5 \\
\mathrm{NT}\end{array}$ & $\begin{array}{c}\mathrm{NT} \\
0.34 \pm 0.2 \\
\end{array}$ & $\begin{array}{c}\mathrm{NT} \\
2.63 \pm 0.7\end{array}$ & $\begin{array}{l}\text { NT } \\
7.74 \\
\end{array}$ \\
\hline $\begin{array}{r}\text { - Control } \\
\text { DMSO }\end{array}$ & NA & NA & NA & NA & NT \\
\hline
\end{tabular}

Ua: Uvaria alba crude extract; UaP: U. alba petroleum ether fraction; UaB: U. alba butanol fraction; UaD: $U$. alba dichloromethane fraction; HepG2: human liver cancer cells; HaCaT: non-tumorigenic human keratinocytes; COX-1 and -2: cyclooxygenase-1 and -2; NT: not tested; NA: no activity

\section{Quantitative LC-MS time-of-flight profiling of the UaB sub-extract}

Given the selective COX-2 inhibitory activity of UaB, the secondary metabolites present in the sub-extract were identified through high resolution LC-MS. The LC-MS profile highlighted the presence of a large group of compounds corresponding to the protonated molecular ions of different polyphenols. Individual components were identified by comparing their $\mathrm{m} / \mathrm{z}$ values with those reported in a public repository of mass spectral data (Figure 1; Table S1). Seven compounds were detected, including the flavonol aglycones quercetin (4) and kaempferol (6) and their glycosylated derivatives such as quercitrin (3), rutin (5), and kaempferol 3-O-rutinoside (7). Among the flavonol-containing secondary metabolites, compounds 5 and 7 were the most abundant comprising $53.12 \%$ and $23.7 \%$ in the bioactive butanol sub-extract. Detected in minimal concentration were the compounds coumarin (2), a benzopyrone, and methyl 3-(3,5-dimethoxy-4((3,4,5-trihydroxy-6-(hydroxymethyl)tetrahydro-2 $H$-pyran-2-yl)oxy) 
phenyl)propanoate (1) which comprised about $1.73 \%$ and $2.77 \%$ in the sub-extract, respectively.

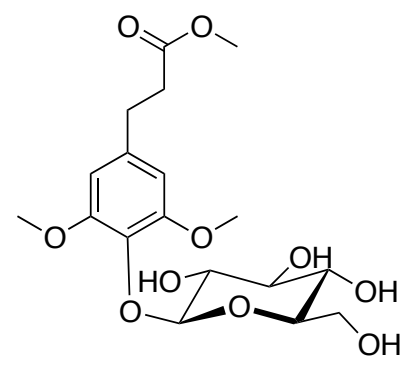

(1)<smiles>O=c1c(O)c(-c2ccc(O)c(O)c2)oc2cc(O)cc(O)c12</smiles>

(4)<smiles>O=c1ccc2ccccc2o1</smiles>

(2)<smiles>O=c1c(OC2OC(CO)C3OC2C(O)C3O)c(-c2ccc(O)c(O)c2)oc2cc(O)cc(O)c12</smiles>

(3)

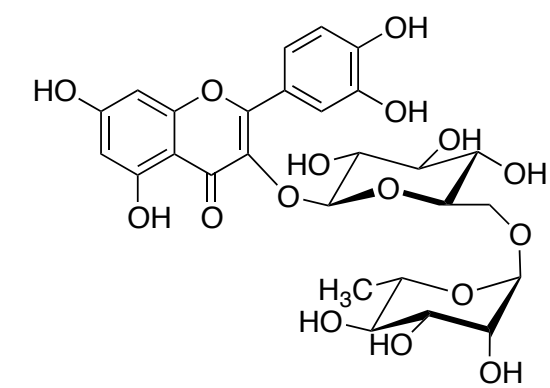<smiles>O=c1c(O)c(-c2ccc(O)cc2)oc2cc(O)cc(O)c12</smiles>

(6)

(5)

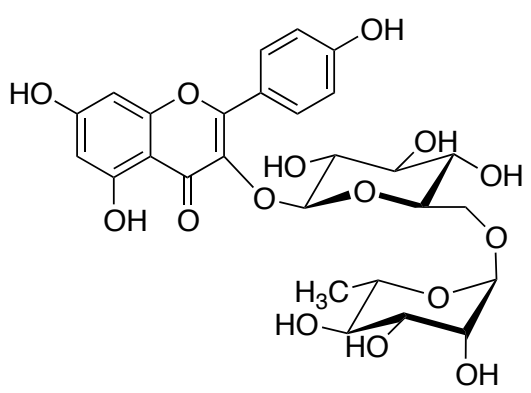

(7)

Figure 1. Secondary metabolites 1-7 detected in the butanol sub-extract of $U$. alba.

\section{Effect of $U$. alba butanol sub-extract (UaB) on the viability of $R A W 264.7$ macrophages}

UaB was non-cytotoxic to RAW 264.7 macrophages in concentrations up to $80 \mathrm{ng} / \mathrm{mL}$ with $100 \%$ viability (Figure 2). Furthermore, upon introduction with LPS, all cells in the culture medium remained viable. Since the $\mathrm{UaB}$ concentration up to $80 \mathrm{ng} / \mathrm{mL}$ was non-cytotoxic, this 
was then used as the maximum screening concentration for evaluating the inflammatory modulating effects of UaB in LPS-challenged RAW 264.7 macrophages.

A

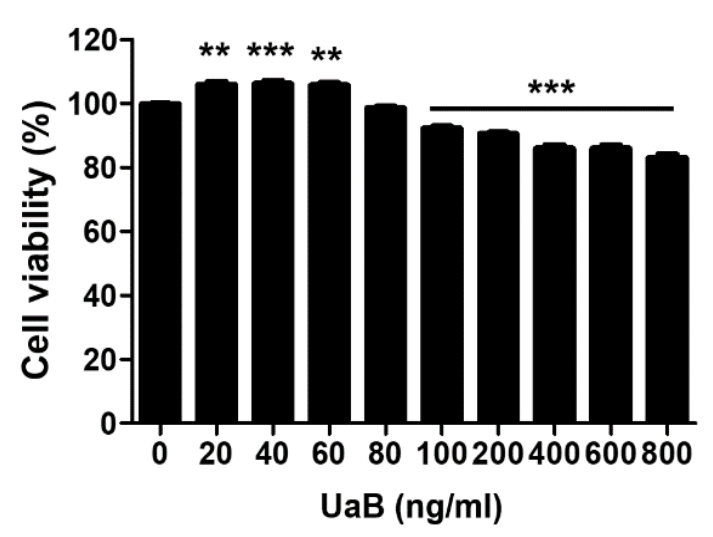

B

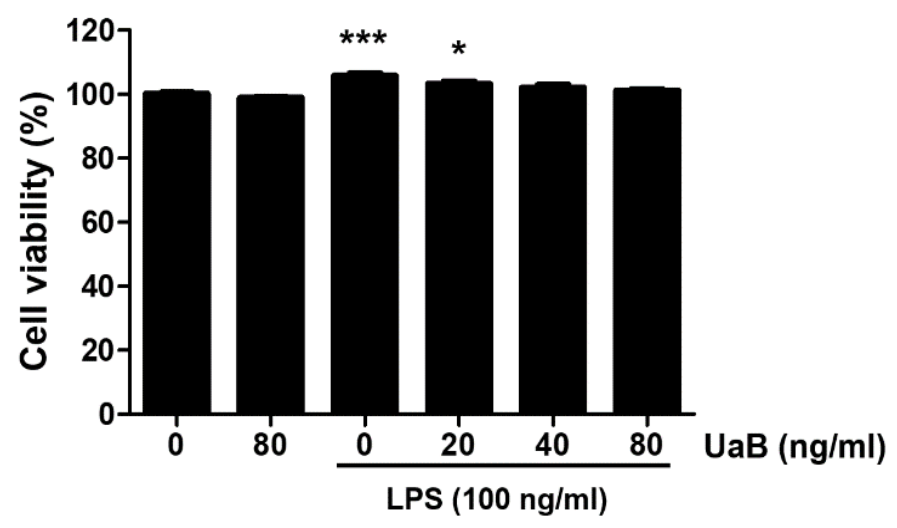

Figure 2. Effect of UaB sub-extract and LPS on the cell viability of RAW 264.7 macrophages. RAW 264.7 cells were stimulated with different concentrations of UaB alone for $24 \mathrm{~h}$ (A) or pretreated with or without $\mathrm{UaB}$ for $1 \mathrm{~h}$ before $100 \mathrm{ng} / \mathrm{mL}$ LPS stimulation for $24 \mathrm{~h}$ (B). Cell viability was analyzed using the MTT assay. Each value indicates the mean \pm SD of three independent experiments. Significant differences among the groups were determined $\left({ }^{*} p<0.05\right.$, $* * p<0.01$ and $* * * p<0.0001$, compared with the control cells).

\section{Effects of UaB on LPS-induced production of proinflammatory mediators}

Stimulation of RAW 264.7 macrophages with LPS alone significantly increased the production of $\mathrm{NO}$ and $\mathrm{PGE}_{2}$ in the culture medium. However, upon introduction with $\mathrm{UaB}$, there was a dose-dependent decline in proinflammatory mediators (Figure 3). Additionally, western blotting analysis and RT-PCR were performed to determine the effects of UaB in protein and mRNA expression of iNOS and COX-2, respectively (Figure 3). Experimental data showed that there was a significant reduction in the expression of iNOS and COX-2 following the introduction of $\mathrm{UaB}$ as indicated by the fading of the bands at $80 \mathrm{ng} / \mathrm{mL}$, and thus suppressing the biosynthesis of $\mathrm{NO}$ and $\mathrm{PGE}_{2}$ in LPS-challenged RAW 264.7 macrophages, respectively. 

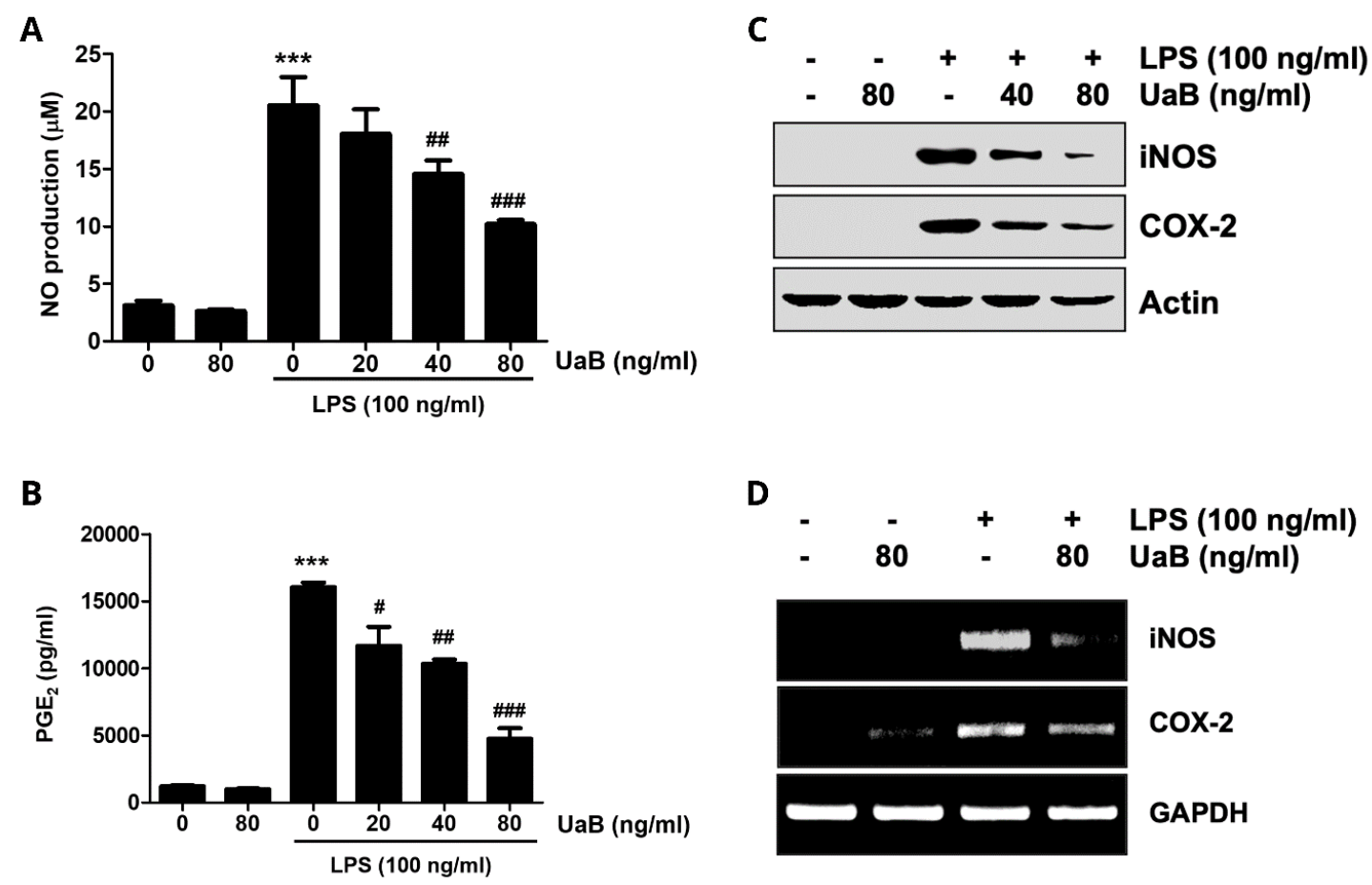

D

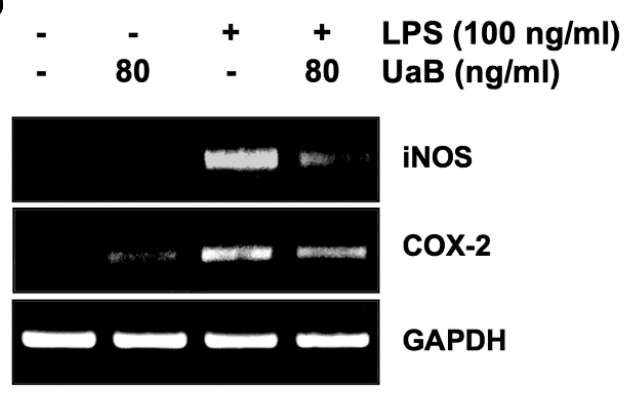

Figure 3. Inhibition of NO and PGE2 production by UaB sub-extract in LPS-stimulated RAW 264.7 macrophages. RAW 264.7 cells were incubated for $1 \mathrm{~h}$ with the indicated concentrations of $\mathrm{UaB}$ prior to stimulation with $100 \mathrm{ng} / \mathrm{mL}$ LPS for $24 \mathrm{~h}$ (A and B). The amounts of (A) NO and (B) $\mathrm{PGE}_{2}$ in the culture supernatants were determined via the Griess reaction and a commercial ELISA kit, respectively. Values are expressed as the mean $\pm \mathrm{SD}$ of results from three independent experiments. ${ }^{* * *} p<0.0001 \quad v s$. controls (UaB- and LPS-untreated cells); ${ }^{\#} p<0.001$ and

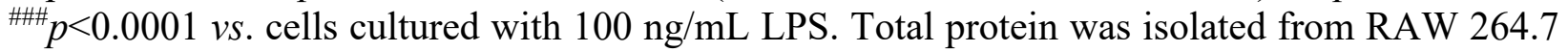
cells pretreated with the indicated concentrations of $U$ aB followed by treatment with $100 \mathrm{ng} / \mathrm{mL}$ LPS for $24 \mathrm{~h}$ and subjected to SDS-PAGE. Western blot analysis was performed using the indicated antibodies and an enhanced chemiluminescence detection system (C). RAW 264.7 cells were pretreated with various concentrations of $\mathrm{UaB}$ for $1 \mathrm{~h}$ followed by treatment with $100 \mathrm{ng} / \mathrm{mL}$ LPS for $24 \mathrm{~h}$. The total RNA was isolated and the mRNA expression of iNOS and COX-2 was analyzed using RT-PCR (D). The experiments were repeated three times and similar results were obtained. Actin and GAPDH were used as internal controls for the western blot and the RT-PCR assays, respectively. NO, nitric oxide; PGE2, prostaglandin E2; RT-PCR, reverse transcriptionpolymerase chain reaction; LPS, lipopolysaccharide; iNOS, inducible NO synthase; COX, cyclooxygenase.

\section{Effects of UaB on LPS-induced production of proinflammatory cytokines}

The stimulation of RAW 264.7 macrophages with LPS alone significantly increased the production of TNF- $\alpha$, IL-1 $\beta$, and IL-6 in the culture medium. However, there was an apparent dose-dependent decline in the production of proinflammatory cytokines upon introduction of $\mathrm{UaB}$ 
(Figure 4). To determine the effect of $\mathrm{UaB}$ in the protein and mRNA expression of these cytokines, western blotting and RT-PCR testing were performed respectively (Figure 4). Experimental data showed significant reduction in the expression of TNF- $\alpha$, IL-1 $\beta$, and IL-6 following the introduction of $\mathrm{UaB}$ as indicated by the fading of the bands at $80 \mathrm{ng} / \mathrm{mL}$.

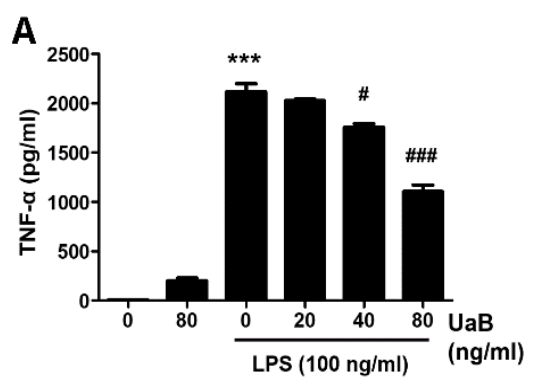

D
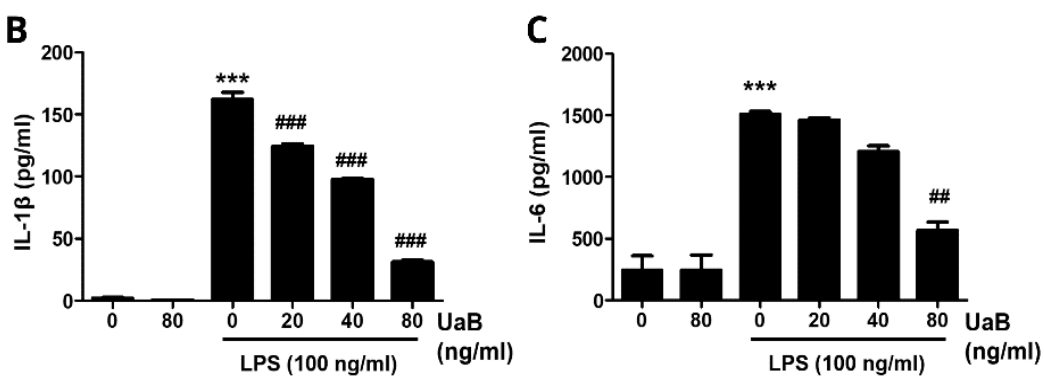

E
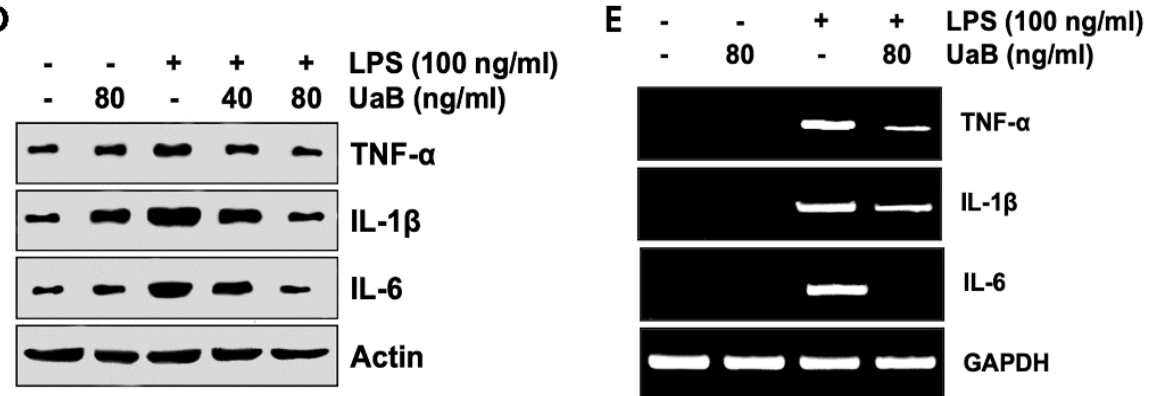

Figure 4. Inhibition of TNF- $\alpha$, IL- $1 \beta$ and IL-6 production by UaB sub-extract in LPS-stimulated RAW 264.7 macrophages. RAW 264.7 cells were incubated for $1 \mathrm{~h}$ with the indicated concentrations of UaB prior to stimulation with LPS $(100 \mathrm{ng} / \mathrm{mL})$ for $24 \mathrm{~h} \mathrm{(A,} \mathrm{B} \mathrm{and} \mathrm{C).} \mathrm{The}$ amounts of (A) TNF- $\alpha$, (B) IL-1 $\beta$ and (C) IL-6 in the culture supernatants were determined using commercial ELISA kits. Values are expressed as the mean \pm SD of results obtained from three independent experiments. ${ }^{* * *} p<0.0001$ vs. controls (UaB- and LPS-untreated cells); ${ }^{*} p<0.01$, ${ }^{\# \#} p<0.001$ and ${ }^{\# \#} p<0.0001$ vs. cells cultured with $100 \mathrm{ng} / \mathrm{mL}$ LPS). Total protein was isolated from RAW 264.7 cells pretreated with the indicated concentrations of $\mathrm{UaB}$ followed by treatment with $100 \mathrm{ng} / \mathrm{mL}$ LPS for $24 \mathrm{~h}$ and subjected to SDS-PAGE. Western blot analyses were performed using the indicated antibodies and an enhanced chemiluminescence detection system (D). RAW 264.7 cells were pretreated with UaB for $1 \mathrm{~h}$ followed by treatment with $100 \mathrm{ng} / \mathrm{mL}$ LPS for $24 \mathrm{~h}$, and the total RNA was isolated. The mRNA expression of TNF- $\alpha$, IL-1 $\beta$ and IL- 6 was analyzed using RT-PCR (E). The experiments were repeated three times, and similar results were obtained. Actin and GAPDH were used as internal controls for the western blot and RT-PCR assays, respectively. IL, interleukin; TNF, tumor necrosis factor; RT-PCR, reverse transcriptionpolymerase chain reaction; LPS, lipopolysaccharide. 


\section{Effects of UaB on LPS-induced nuclear translocation of NF-кB}

The effect of UaB in the NF-kB signaling pathway was further explored in this study. Figure 5 shows the possible impairment of the NF- $\mathrm{BB}$ activation when LPS-challenged macrophages were treated with $\mathrm{UaB}$, as appreciated by the decreased enhancement on immunofluorescence staining in comparison with that of untreated LPS-induced macrophages. Moreover, the effect of $\mathrm{UaB}$ on the nuclear translocation of NF- $\mathrm{kB}$ p65 was also observed in the western blot analysis since a more prominent band is seen in the LPS-induced macrophage, while there is a lighter band in the UaB treated sample. 
A

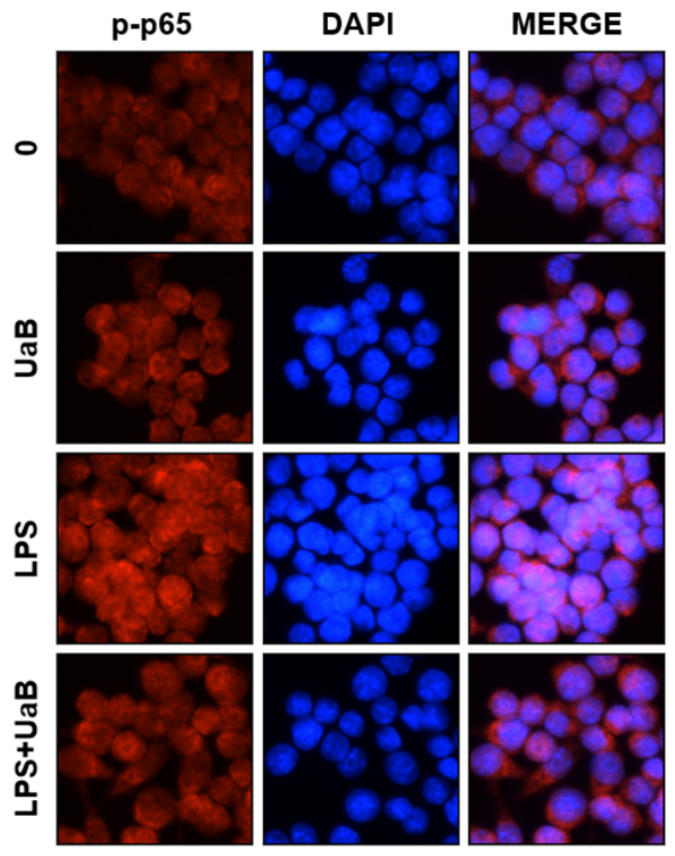

B

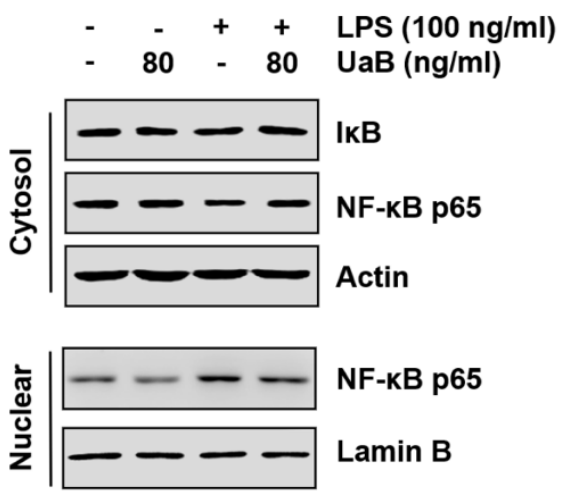

Figure 5. Effect of UaB sub-extract on LPS-induced nuclear translocation of NF- $\kappa \mathrm{B}$ in RAW 264.7 macrophages. The cells were treated with $80 \mathrm{ng} / \mathrm{mL} \mathrm{UaB}$ for $1 \mathrm{~h}$ prior to treatment with 100 $\mathrm{ng} / \mathrm{mL}$ LPS for $30 \mathrm{~min}$. (A) The cells were pretreated with $80 \mathrm{ng} / \mathrm{mL} \mathrm{UaB}$ for $1 \mathrm{~h}$ prior to stimulation with $100 \mathrm{ng} / \mathrm{ml}$ LPS for $30 \mathrm{~min}$. Localization of NF- $\kappa \mathrm{B}$ p65 was visualized following immunofluorescence staining with anti-NF- $\kappa \mathrm{B}$ p 65 antibody (red). The cells were also stained with DAPI for visualization of nuclei (blue). The cells were visualized using a fluorescence microscope (magnification, $\mathrm{x} 400$ ). (B) The cells were pretreated with $80 \mathrm{ng} / \mathrm{mL} \mathrm{UaB}$ for $1 \mathrm{~h}$ prior to stimulation with $100 \mathrm{ng} / \mathrm{mL}$ LPS for $30 \mathrm{~min}$. Nuclear and cytosolic proteins were subjected to $10 \%$

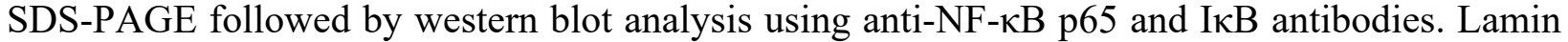
$\mathrm{B}$ and actin were used as internal controls for the nuclear and cytosolic fractions, respectively. NF,

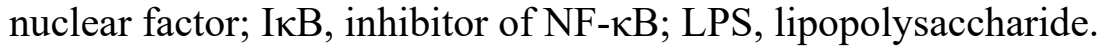

\section{Molecular docking to iNOS, COX-1/2, TACE, TNF- $\alpha$ and IKK}

The flavonoid metabolites of $U$. alba were subjected to molecular docking analysis against cyclooxegenases COX-1 and COX-2. Structurally, these two enzymes consist of a long rounded tunnel which serves as the catalytic domain. Being bifunctional enzymes, cyclooxygenases are involved in catalyzing two sequential redox reactions, where both active sites are located at 
opposite sides of the catalytic tunnel. For this study, various binding regions of both COX-1 and COX-2 were investigated for their potentials to accommodate $U$. alba flavonoid binding: (a) cyclooxygenase active site or the NSAID-binding site where oxygenation of arachidonic acid occurs; (b) peroxidase (POX) active site at the end of the catalytic tunnel where reduction of PGG2 to PGH2 occurs; and (c) a hydrophilic side chain which serves as entry to the catalytic tunnel. At the NSAID-binding site of COX-2, the flavonol aglycones $\mathbf{4}$ and $\mathbf{6}$ exhibited the best binding with binding energies (BE's) of -9.6 and $-9.4 \mathrm{kcal} / \mathrm{mol}$, respectively. In particular, the polycyclic core of quercetin (4) is bound onto the binding pocket via pi-alkyl interactions with hydrophobic amino acids Val335, Leu338, and Val509. Additionally, a conventional hydrogen bonding with the C7$\mathrm{OH}$ against Gln78 and Phe504 strengthened 4's attachment to the site. As for the POX active site of COX-2, the larger glycosylated flavonols 5 and 7 showed highest binding propensities with BE's of -8.1 and $-8.2 \mathrm{kcal} / \mathrm{mol}$, respectively. In the case of compound 7's attachment to the POX active site, it is predominantly held by hydrophilic interactions, such as pi-anion attraction between the A ring of the flavonoid core and the heme group as well as hydrogen bonding between $\mathrm{C} 7-\mathrm{OH}$ and His207/Phe210 and hydroxyls of the sugar moiety and Arg222. Additional hydrophobic interactions between the C-ring against His214 (T-shaped $\pi-\pi$ ) and the Val291 (pi-alkyl) and between the B-ring and Ile274 (pi-alkyl). At the COX-2 side pocket, it is the glycosylated metabolites $5(-8.6 \mathrm{kcal} / \mathrm{mol})$ and $7(-8.5 \mathrm{kcal} / \mathrm{mol})$ which displayed strong binding. The selected binding region serves as an entrance to the narrow catalytic tunnel which are lined with polar residues and thus cater more to larger polyhydroxylated ligands such as compounds $\mathbf{5}$ and $\mathbf{7}$. Rutin (5) is nestled the binding pocket mostly by polar interactions, specifically four conventional Hbonding: (a) C7-OH and Pro500, (b) C3'-OH and Lys82, and (c) hydroxyls of the sugar moiety and Asn89 and Gln336. Molecular docking of the metabolites against COX-1 (PDB ID: 3KK6) 
showed that the kaempferol (6) had the better binding towards the NSAID-binding site (BE $=-7.9$ $\mathrm{kcal} / \mathrm{mol}$ ), however, the compound still showed better selectivity towards COX-2.

The flavonoids were also subjected to molecular docking analysis against other receptors, such as tumor necrosis factor-alpha (TNF- $\alpha$ ), TNF- $\alpha$ converting enzyme (TACE), and inducible nitric oxide synthase (iNOS). As for TACE, quercetin (4) demonstrated the highest binding with a BE of $-9.3 \mathrm{kcal} / \mathrm{mol}$. On the $\mathrm{B}$ ring of the flavonoid core of 4 , its hydroxyl group of the $\mathrm{B}$ ring is held by two sets of interactions: (a) hydrogen bonding with His405 and Ile438 and (b) unfavorable donor-donor interaction with Tyr436 and Val440. Meanwhile, the aromatic B-ring is held by pialkyl interactions with Val402 and Ala439. Other hydroxyl substituents of the A/B rings of 4 showed hydrogen bonding with Gly346, Thr347, and Ala439. Another aglycone, kaempferol (6), exhibited strong binding affinity $(\mathrm{BE}=-8.4 \mathrm{kcal} / \mathrm{mol})$ towards the putative binding site of TNF- $\alpha$ trimer which is generally held by hydrophobic interactions. The A and B rings of 6 are bound through $p i-p i$ stacking with Tyr135 (chain A of the trimer) and pi-alkyl interplay with Leu133 residues (both chains A and B). The hydroxyphenol moiety of $\mathbf{6}$, on the other hand, is bound by $p i$-alkyl interaction with Leu133 (chain C) and hydrogen bonding with Leu233 (chain A). For the docking analysis against iNOS docking, both glycosylated flavonoids rutin (5) and kaempferol 3O-rutinoside (7) demonstrated high affinity with BE's of $-10.0 \mathrm{kcal} / \mathrm{mol}$. Both compounds are nestled to the binding site of iNOS strengthened mostly by hydrophilic interactions. The hydroxyl groups of the sugar moiety formed H-bonding against Arg199, Tyr347, Tyr373, Asp382, Arg388, and Trp463. The flavonoid core, on the other hand, interacted with Ile201 and Tyr491 via Hbonding and with Cys200 and Val352 via pi-alkyl interplay.

Finally, the putative UaB metabolites were docked against IкB kinase (IKK). Among the metabolites, rutin (5) demonstrated a strong binding towards the IKK $(\mathrm{BE}=-10.7 \mathrm{kcal} / \mathrm{mol})$. The 
flavonoid core of 5 is affixed to the binding pocket through pi-alkyl interactions with Leu13, Val21, Lys36, Val144, and Ile157. A conventional hydrogen bonding is also observed between the hydroxyl group of the B ring versus Lys36 and Glu53. The sugar moiety of $\mathbf{5}$ is held by Hbonding against Asn142 and C-H bonding against Thr15.

\section{MD simulation of top-ranked ligands in complex with iNOS, COX-1/2, TACE, TNF- $\alpha$ and IKK}

Understanding the structural dynamic features is an important parameter to reveal the binding of ligands to a specific receptor. Herein, using MD simulation approach, we performed structural stability and residual flexibility analysis to understand the binding stability of each ligand. Structural stability calculated as root mean square deviation (RMSD) as a function of time revealed that all the ligands bind stably in the binding cavity except for some minor deviations in a particular complex. In case of COX2-NSAID, the structure demonstrated a little unstable behavior between $100-140 \mathrm{~ns}$ while the average RMSD was calculated to be $2.5 \AA$. Moreover for all the complexes remained lower comparatively and demonstrated average RMSD between 2.0$2.5 \AA$, respectively. This shows the stable binding of these ligands into the binding cavity of the respective receptors. The RMSD graphs of all the complexes are given in Figure 7.

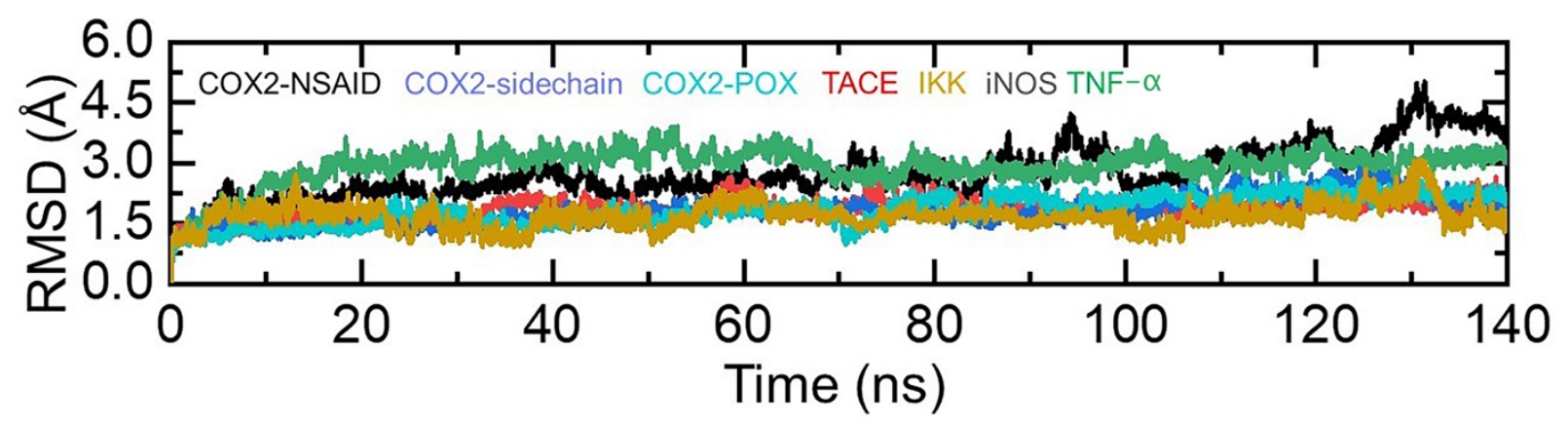

Figure 7. Dynamics stability investigation of all the ligands inside the binding cavity over 140ns simulation time. Each complex is represented with different colors. 
To understand the residual flexibility which confers an important role in biological processes and demonstrate the strength of binding we used root mean square fluctuation (RMSF) approach to calculate the flexibility. As given in Figure 8, the COX2-NSAID, COX2-sidechain and COX2-POX demonstrated more similar pattern of flexibility except for some regions such as 1-100aa, 300-350aa and 480-530aa which is due to the differential binding of ligands which consequently produces different internal dynamics of the residues. Moreover the RMSF for other complexes including TACE, IKK, iNOS, and TNF- $\alpha$ revealed acceptable fluctuation of the residues. In particular, the TNF- $\alpha$ can be seen to have impacted the residues' flexibility by minimizing the flexibility of the residues thus showing the stable binding and alteration of internal dynamics. Like the RMSD, the RMSF is also demonstrating similar behavior consequently favoring the stable binding of ligands. The RMSF of each complex is given in Figure 8.
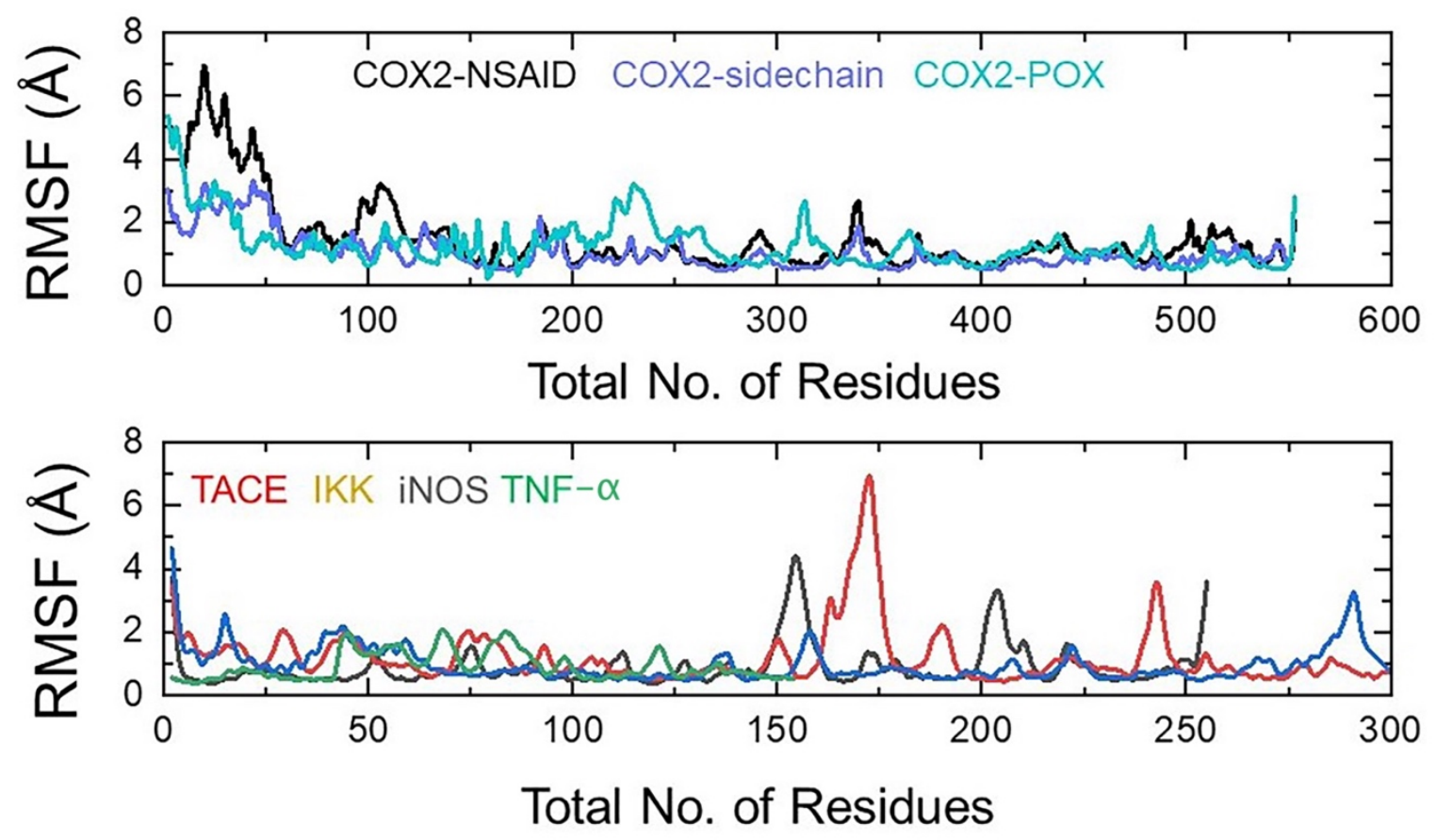

Figure 8. Residual Flexibility investigation of all the ligands inside the binding cavity over 140ns simulation time. Each complex is represented with different colors. 
Binding free energy prediction of small molecules to a larger biological macromolecule by MM/GBSA is arguably the most widely used approach to re-investigate docking conformation, determining structural stability and predicting interacting hotspots and binding affinities. The aforementioned method is computationally less expensive than the extensive alchemical free energy methods and is categorized as more accurate than conventional scoring functions. Taking into account the high significance of this method, we calculate the total binding free energy for each complex. For each complex COX2-NSAID (-25.23), COX2-sidechain (-22.74), COX2-POX (-26.53), TACE (-29.08), IKK (-23.24), iNOS (-22.11), and TNF- $\alpha$ reported $-35.96 \mathrm{kcal} / \mathrm{mol}$. This shows that for these ligands, particularly TNF- $\alpha$, the binding was robust. The other energy terms such as vdW, electrostatic, SA and GB are also given in Table 4.

Table 4. Binding free energy calculation results calculated in $\mathrm{kcal} / \mathrm{mol}$.

\begin{tabular}{cccccc}
\hline Complexes & vdW & electrostatic & SA & GB & Total \\
\hline COX2-NSAID & -16.47 & -25.58 & -6.33 & 23.15 & $\mathbf{- 2 5 . 2 3}$ \\
\hline COX2-sidechain & -13.23 & -29.92 & -4.87 & 25.28 & $\mathbf{- 2 2 . 7 4}$ \\
\hline COX2-POX & -17.66 & -35.38 & -3.37 & 29.88 & $\mathbf{- 2 6 . 5 3}$ \\
\hline TACE & -18.28 & -17.62 & -7.41 & 14.23 & $\mathbf{- 2 9 . 0 8}$ \\
\hline IKK & -26.36 & -21.77 & -5.32 & 30.21 & $\mathbf{- 2 3 . 2 4}$ \\
\hline iNOS & -31.52 & -17.1 & -2.11 & 28.62 & $\mathbf{- 2 2 . 1 1}$ \\
\hline TNF- $\alpha$ & -25.28 & -21.22 & -5.47 & 16.01 & $\mathbf{- 3 5 . 9 6}$ \\
\hline
\end{tabular}

vdW: van der Waals; SA: surface accessible; GB: generalized born

\section{Discussion}

Inflammation is the body's natural defense against invading pathogens, toxins, and physical trauma (Hung and Suzuki, 2017). However, an overreactive inflammatory response is also associated with autoimmune and neurodegenerative diseases, anaphylactic reactions, and cancer development (Hung and Suzuki, 2017). Thus, there have been efforts to discover and design immunomodulatory compounds to overcome the unwanted sequelae of an overwhelming 
inflammatory process (Yamamoto and Gaynor, 2005). In this study, we investigated the inflammatory modulating properties of butanol sub-extract from U. alba (UaB). Utilizing enzymebased assay, our initial screening revealed that UaB selectively inhibited COX-2, the key enzyme mediating the conversion of arachidonic acid to prostaglandins (Chen et al., 2018). To further confirm this result, we investigated in vitro the potential of $\mathrm{UaB}$ in attenuating proinflammatory mediators and cytokines in LPS-challenged RAW 264.7 macrophages. Our results revealed that UaB suppressed the synthesis of $\mathrm{NO}$ and $\mathrm{PGE}_{2}$ by downregulating protein and mRNA expression of iNOS and COX-2, respectively. These proinflammatory mediators induce oxidative stress and play an integral part in the progression of chronic inflammatory diseases (Muniandy et al., 2018). Thus, $\mathrm{NO}$ and $\mathrm{PGE}_{2}$ are potential therapeutic targets for modulating inflammatory-associated pathologies (Choi et al., 2014; Park et al., 2021). Furthermore, our experimental data reported the significant reduction of proinflammatory cytokines in LPS-challenged macrophages by downregulating protein and mRNA expression of TNF- $\alpha$, IL-1 $\beta$, and IL-6. Similar to proinflammatory mediators, these cytokines have chemotactic and vasoactive properties (Muniandy et al., 2018). TNF- $\alpha$, in particular, upregulates proinflammatory cytokines, promotes

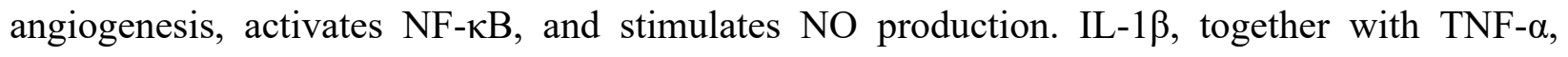
induces fever, causes coagulation associated with inflammatory response, and induces severe inflammatory cascade through autocrine and paracrine mechanisms (Hung and Suzuki, 2017). Meanwhile, IL-6 is associated with chronic inflammation and serves as an inducer of acute phase reactants, B cells, and T lymphocytes (Hung and Suzuki, 2017; Limtrakul et al., 2015). Thus, inhibition of cytokines could attenuate severe and potentially fatal inflammatory cascade (Fang et al., 2021; Novilla et al., 2017). 
Interestingly, the production of proinflammatory mediators and cytokines is further regulated by the all-encompassing NF-kB signalling pathway. In this study, we demonstrated the potential of $\mathrm{UaB}$ in suppressing NF- $\mathrm{kB}$ activation. Nuclear translocation of NF- $\mathrm{KB}$ is necessary for the transcription of proinflammatory mediators and cytokines. In the cytosol, NF-kB is inactive until IאB is phosphorylated through the initiation of IKK (Liu et al., 2017; Tak and Firestein, 2001). Hence, the role of $\mathrm{UaB}$ in suppressing nuclear translocation of NF- $\mathrm{KB}$ p65 is an indication of its mechanistic anti-inflammatory property thereby downregulating the expression of proinflammatory mediators and cytokines (Figure 6). Several natural products have been shown to suppress inflammatory response through this mechanism. Anthocyanin from black rice extract and carvacrol, a phenolic monoterpene, from essential oil of the Lamiaceae family, both abrogated nuclear translocation of NF-kB (Limtrakul et al., 2015; Somensi et al., 2019). Thus, bioprospecting involving endemic plants such as $U$. alba can be the key to the discovery of anti-inflammatory compounds that can modulate the NF- $\mathrm{kB}$ signaling pathway. 

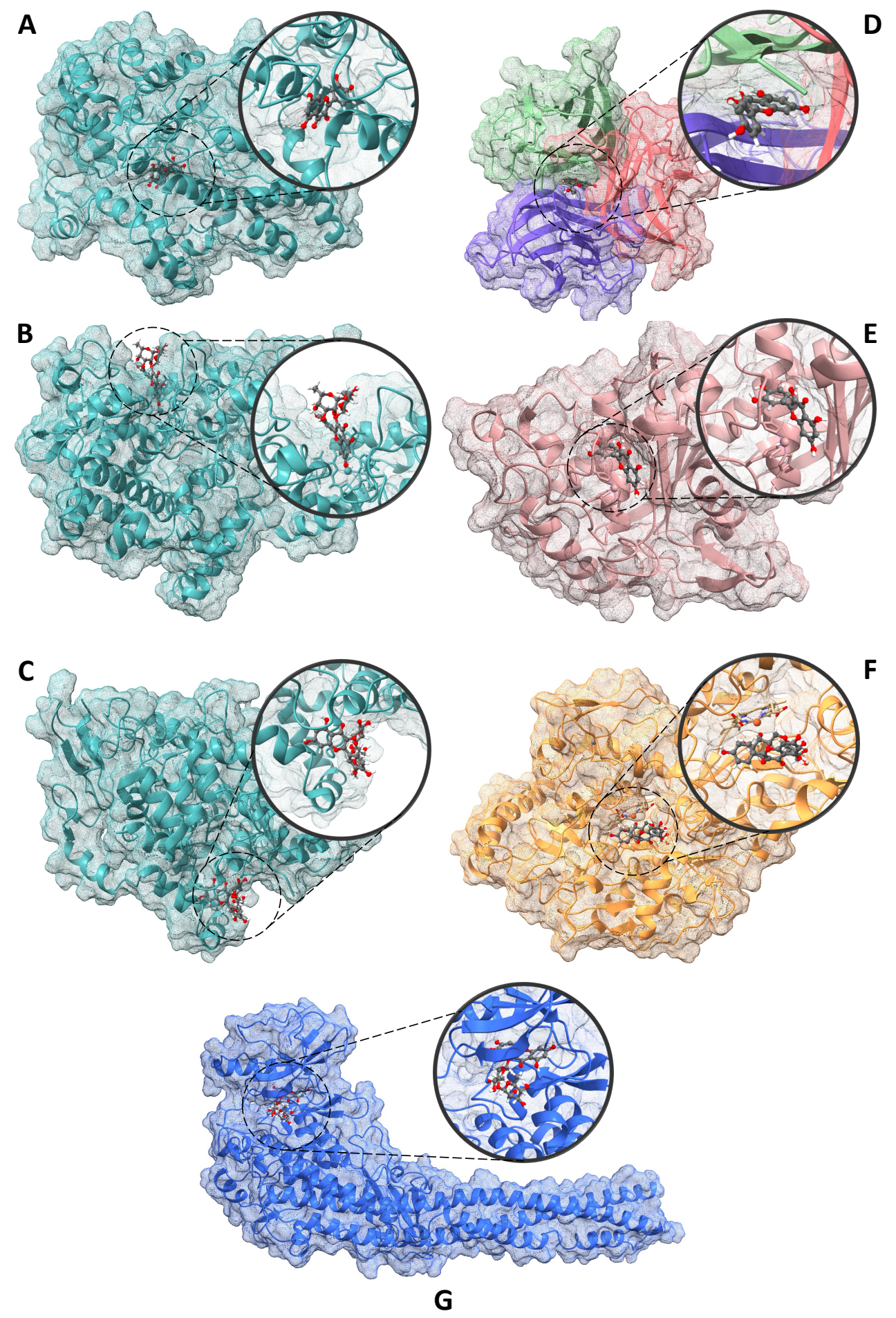

Figure 6. Docked poses of (A) quercetin (4) against COX-2 NSAID-binding site (PDB ID: 4M11); (B) kaempferol 3-O-rutinoside (7) against COX-2 POX-binding site (PDB ID: 4M11); (C) rutin (5) against COX-2 side chain (PDB ID: 4M11); (D) kaempferol (6) against TNF- $\alpha$ (PDB ID: 1TNF); (E) quercetin (4) against TACE (PDB ID: 3KME); kaempferol 3-O-rutinoside (7) against iNOS (PDB ID: 4NOS); and rutin (5) against IKK (PDB ID: 4KIK). 
Based on HR-LC-MS profiling of the UaB sub-extract, the majority of the putatively identified metabolites are flavonoids. Flavonoids have been known to display anti-inflammatory properties via a variety of mechanisms, including inhibition of regulatory enzymes and transcription factors, both of which play essential roles in the regulation of mediators implicated in inflammation. The more abundant metabolites in the UaB sub-extract are quercetin (4), rutin (5), kaempferol (6) and kaempferol 3-O-rutinoside (7) which individually have been shown to be anti-inflammatory agents via in vitro and in vivo experiments (Kong et al., 2013; Li et al., 2016; Oyagbemi et al., 2018; Wang et al., 2018). To further evaluate the role of UaB sub-extract as an anti-inflammatory, we investigated the binding behavior of the putative metabolites of $\mathrm{UaB}$ through molecular docking and molecular dynamic simulation methodologies against proinflammatory enzymes. In the docking analysis of the metabolites against COX-2, the compounds were found to bind to various active sites of the enzyme which probably inhibit specific enzymatic activities of COX-2. In particular, the smaller flavonol aglycones bind strongly to NSAID-binding site situated at the middle of a narrow tunnel, while the larger glycosylated flavonols preferred binding at the peroxidase binding site and at hydrophilic sidechain, an entry to the cyclooxygenase tunnel. The various mechanisms of attachment at different catalytic sites of the UaB metabolites suggest a potentially strong COX-2-inhibitory activity of the sub-extract which corroborates with the in vitro data. The flavonoids also show selectivity towards COX-2 over COX-1. Moreover, molecular docking analysis revealed that the aglycones exhibited high affinity towards TNF- $\alpha$, and TACE, while the glycosylated flavonoids showed high affinity towards iNOS and IKK. The top protein-ligand complexes of these enzymes and respective flavonoids were also found to be dynamically stable. These computational data, as confirmed by in vitro analysis, suggest the anti- 
inflammatory potential of the UaB sub-extract. Finally, these data may help in the understanding of the key roles of flavonoids in the regulation of inflammatory responses which are valuable in the discovery of drug leads for the prevention, mitigation, and treatment of many chronic inflammatory illnesses (Maleki et al., 2019; Pan et al., 2010; Quimque et al., 2021a).

\section{Conclusion}

Compelling evidence showed that putative flavonoids from $U$. alba butanol sub-extract (UaB) ameliorate inflammatory responses in LPS-challenged Raw 264.7 macrophages by attenuating the production of proinflammatory mediators (NO and $\left.\mathrm{PGE}_{2}\right)$ and cytokines (TNF- $\alpha$, IL- $1 \beta$, and IL6) through the downregulation of their protein and mRNA expression. Furthermore, UaB was found to attenuate NF- $\mathrm{KB}$ activation by inhibiting the nuclear translocation of the transcription factor p65. Finally, the putative metabolites of $\mathrm{UaB}$, particularly the aglycone and glycosylated flavonols, were found to exhibit good binding and form stable complexes with various active sites of COX-2 as well as with the binding pocket of TNF- $\alpha$-, TACE, iNOS, and IKK based on molecular docking analysis and molecular dynamic simulations. This is the first report highlighting the mechanistic in silico and in vitro anti-inflammatory potential of the Philippine endemic plant, U. alba. Thus, further in vivo experimentations are encouraged to validate the potent antiinflammatory properties of the said endemic medicinal plant.

\section{Declaration of competing interest}

The authors declare no competing interest in this work. 


\section{References}

Ali, A., Khan, M.T., Khan, A., Ali, S., Chinnasamy, S., Akhtar, K., Shafiq, A., Wei, D.-Q., 2020. Pyrazinamide resistance of novel mutations in pncA and their dynamic behavior. RSC Adv. 10, 35565-35573. https://doi.org/10.1039/D0RA06072K

Biswas, R., Bagchi, A., 2016. NFkB pathway and inhibition: an overview. Comput. Mol. Biol. 6, 1-20. https://doi.org/10.5376/cmb.2016.06.0001

Brogi, S., Quimque, M.T., Notarte, K.I., Africa, J.G., Hernandez, J.B., Tan, S.M., Calderone, V., Macabeo, A.P., 2022. Virtual Combinatorial Library Screening of Quinadoline B

Derivatives against SARS-CoV-2 RNA-Dependent RNA Polymerase. Comput. 2022, Vol. 10, Page 7 10, 7. https://doi.org/10.3390/COMPUTATION10010007

Case, D.A., Cheatham, T.E., Darden, T., Gohlke, H., Luo, R., Merz, K.M., Onufriev, A., Simmerling, C., Wang, B., Woods, R.J., 2005. The Amber biomolecular simulation programs. J. Comput. Chem. https://doi.org/10.1002/jcc.20290

Chen, L., Deng, H., Cui, H., Fang, J., Zuo, Z., Deng, J., Li, Y., Wang, X., Zhao, L., 2018. Inflammatory responses and inflammation-associated diseases in organs. Oncotarget 9, 7204-7218.

Choi, Y.H., Kim, G.Y., Lee, H.H., 2014. Anti-inflammatory effects of cordycepin in lipopolysaccharide-stimulated RAW 264.7 macrophages through Toll-like receptor 4mediated suppression of mitogen-activated protein kinases and NF- $\kappa$ B signaling pathways. Drug Des. Devel. Ther. 8, 1941-1953. https://doi.org/10.2147/DDDT.S71957

de Leon, V.N.O., Manzano, J.A.H., Pilapil, D.Y.H., Fernandez, R.A.T., Ching, J.K.A.R., Quimque, M.T.J., Agbay, J.C.M., Notarte, K.I.R., Macabeo, A.P.G., 2021. Anti-HIV reverse transcriptase plant polyphenolic natural products with in silico inhibitory properties on seven non-structural proteins vital in SARS-CoV-2 pathogenesis. J. Genet. Eng. Biotechnol. 19, 104. https://doi.org/10.1186/s43141-021-00206-2

Duggan, K.C., Walters, M.J., Musee, J., Harp, J.M., Kiefer, J.R., Oates, J.A., Marnett, L.J., 2010. Molecular basis for cyclooxygenase inhibition by the non-steroidal anti-inflammatory drug naproxen. J. Biol. Chem. 285, 34950-34959. https://doi.org/10.1074/jbc.M110.162982

Fang, Y., Yang, L., He, J., 2021. Plantanone C attenuates LPS-stimulated inflammation by inhibiting NF- $\kappa \mathrm{B} / \mathrm{iNOS} / \mathrm{COX}-2 / \mathrm{MAPKs} / \mathrm{Akt}$ pathways in RAW 264.7 macrophages. Biomed. Pharmacother. 143, 112104. https://doi.org/10.1016/J.BIOPHA.2021.112104

Fernandez, R.A., Quimque, M.T., Notarte, K.I., Manzano, J.A., Pilapil, D.Y., de Leon, V.N., San Jose, J.J., Villalobos, O., Muralidharan, N.H., Gromiha, M.M., Brogi, S., Macabeo, A.P.G., 2021. Myxobacterial depsipeptide chondramides interrupt SARS-CoV-2 entry by targeting its broad, cell tropic spike protein. J. Biomol. Struct. Dyn. 0, 1-12. https://doi.org/10.1080/07391102.2021.1969281

Fujiwara, N., Kobayashi, K., 2005. Macrophages in inflammation. Curr. Drug Targets Inflamm. Allergy 4, 281-286. https://doi.org/10.2174/1568010054022024

Garcia, K.Y.M., Quimque, M.T.J., Primahana, G., Ratzenböck, A., Cano, M.J.B., Llaguno, J.F.A., Dahse, H.M., Phukhamsakda, C., Surup, F., Stadler, M., Macabeo, A.P.G., 2021. COX inhibitory and cytotoxic naphthoketal-bearing polyketides from Sparticola junci. Int. J. Mol. Sci. 22, 1-13. https://doi.org/10.3390/ijms222212379

Hung, Y.L., Suzuki, K., 2017. The pattern recognition receptors and lipopolysaccharides (LPS)induced systemic inflammation. Int. J. Res. Stud. Med. Heal. Sci. 2, 1-7.

Khan, A., Tahir Khan, M., Saleem, S., Junaid, M., Ali, A., Shujait Ali, S., Khan, M., Wei, D.-Q., 
2020. Structural insights into the mechanism of RNA recognition by the N-terminal RNAbinding domain of the SARS-CoV-2 nucleocapsid phosphoprotein. Comput. Struct.

Biotechnol. J. 18, 2174-2184. https://doi.org/10.1016/j.csbj.2020.08.006

Kong, L., Luo, C., Li, X., Zhou, Y., He, H., 2013. The anti-inflammatory effect of kaempferol on early atherosclerosis in high cholesterol fed rabbits. Lipids Health Dis. 12, 1-12. https://doi.org/10.1186/1476-511X-12-115

Kwon, D.H., Cha, H.J., Choi, E.O., Leem, S.H., Kim, G.Y., Moon, S.K., Chang, Y.C., Yun, S.J., Hwang, H.J., Kim, B.W., Kim, W.J., Choi, Y.H., 2018. Schisandrin A suppresses lipopolysaccharide-induced inflammation and oxidative stress in RAW 264.7 macrophages by suppressing the NF- $\kappa \mathrm{B}$, MAPKs and PI3K/Akt pathways and activating Nrf2/HO-1 signaling. Int. J. Mol. Med. 41, 264-274. https://doi.org/10.3892/ijmm.2017.3209

Li, Y., Yao, J., Han, C., Yang, J., Chaudhry, M.T., Wang, S., Liu, H., Yin, Y., 2016. Quercetin, inflammation and immunity. Nutrients 8, 1-14. https://doi.org/10.3390/nu8030167

Limtrakul, P., Yodkeeree, S., Pitchakarn, P., Punfa, W., 2015. Suppression of inflammatory responses by black rice extract in RAW 264.7 macrophage cells via downregulation of NFkB and AP-1 signaling pathways. Asian Pacific J. Cancer Prev. 16, 4277-4283. https://doi.org/10.7314/APJCP.2015.16.10.4277

Liu, T., Zhang, L., Joo, D., Sun, S.C., 2017. NF-кB signaling in inflammation. Signal Transduct. Target. Ther. 2. https://doi.org/10.1038/sigtrans.2017.23

Macabeo, A.P.G., Letada, A.G., Budde, S., Faderl, C., Dahse, H.M., Franzblau, S.G., Alejandro, G.J.D., Pierens, G.K., Garson, M.J., 2017. Antitubercular and Cytotoxic Chlorinated secoCyclohexenes from Uvaria alba. J. Nat. Prod. 80, 3319-3323. https://doi.org/10.1021/acs.jnatprod.7b00679

Macabeo, A.P.G., Martinez, F.P.A., Kurtán, T., Tóth, L., Mándi, A., Schmidt, S., Heilmann, J., Alejandro, G.J.D., Knorn, M., Dahse, H.M., Franzblau, S.G., 2014. Tetrahydroxanthene1,3(2 H)-dione derivatives from Uvaria valderramensis. J. Nat. Prod. 77, 2711-2715. https://doi.org/10.1021/np500538c

Macabeo, A.P.G., Tudla, F.A., Alejandro, G.J.D., Kouam, S.F., Hussain, H., Krohn, K., 2010. Benzoylated derivatives from Uvaria rufa. Biochem. Syst. Ecol. 38, 857-860. https://doi.org/10.1016/j.bse.2010.08.007

Macabeo, A.P.G., Tudla, F.A., Krohn, K., Franzblau, S.G., 2012. Antitubercular activity of the semi-polar extractives of Uvaria rufa. Asian Pac. J. Trop. Med. 5, 777-780. https://doi.org/10.1016/S1995-7645(12)60142-4

Maleki, S.J., Crespo, J.F., Cabanillas, B., 2019. Anti-inflammatory effects of flavonoids. Food Chem. 299, 125124. https://doi.org/https://doi.org/10.1016/j.foodchem.2019.125124

Meza, J.C., 2010. Steepest descent. WIREs Comput. Stat. 2, 719-722. https://doi.org/https://doi.org/10.1002/wics.117

Muniandy, K., Gothai, S., Badran, K.M.H., Kumar, S.S., Esa, N.M., Arulselvan, P., 2018. Suppression of proinflammatory cytokines and mediators in LPS-Induced RAW 264.7 macrophages by stem extract of Alternanthera sessilis via the inhibition of the NF- $\kappa \mathrm{B}$ pathway. J. Immunol. Res. 2018. https://doi.org/10.1155/2018/3430684

Notarte, K.I.R., Devanadera, M.K.P., Mayor, A.B.R., Cada, M.C.A., Pecundo, M.H., Macabeo, A.P.G., 2019. Toxicity, antibacterial, and antioxidant activities of fungal endophytes Colletotrichum and Nigrospora spp. isolated from uvaria grandiflora. Philipp. J. Sci. 148, 503-510.

Novilla, A., Djamhuri, D.S., Nurhayati, B., Rihibiha, D.D., Afifah, E., Widowati, W., 2017. 
Anti-inflammatory properties of oolong tea (Camellia sinensis) ethanol extract and epigallocatechin gallate in LPS-induced RAW 264.7 cells. Asian Pac. J. Trop. Biomed. 7, 1005-1009. https://doi.org/10.1016/J.APJTB.2017.10.002

Oyagbemi, A.A., Omobowale, T.O., Ola-Davies, O.E., Asenuga, E.R., Ajibade, T.O., Adejumobi, O.A., Afolabi, J.M., Ogunpolu, B.S., Falayi, O.O., Ayodeji, F., Hassan, F.O., Saba, A.B., Adedapo, A.A., Yakubu, M.A., 2018. Ameliorative effect of Rutin on sodium fluoride-induced hypertension through modulation of Kim-1/NF- $\kappa \mathrm{B} / \mathrm{Nrf} 2$ signaling pathway in rats. Environ. Toxicol. 33, 1284-1297. https://doi.org/10.1002/tox.22636

Pan, M.H., Lai, C.S., Ho, C.T., 2010. Anti-inflammatory activity of natural dietary flavonoids. Food Funct. 1, 15-31. https://doi.org/10.1039/c0fo00103a

Park, C., Cha, H.J., Lee, H., Kim, G.Y., Choi, Y.H., 2021. The regulation of the TLR4/NF-кB and $\mathrm{Nrf} 2 / \mathrm{HO}-1$ signaling pathways is involved in the inhibition of lipopolysaccharideinduced inflammation and oxidative reactions by morroniside in RAW 264.7 macrophages. Arch. Biochem. Biophys. 706, 108926. https://doi.org/10.1016/j.abb.2021.108926

Park, S., Kim, M., Hong, Y., Lee, H., Tran, Q., Kim, C., Kwon, S.H., Park, Jisoo, Park, Jongsun, Kim, S.H., 2020. Myristoylated TMEM39AS41, a cell-permeable peptide, causes lung cancer cell death. Toxicol. Res. 36, 123-130. https://doi.org/10.1007/s43188-020-00038-1

Pearlman, D.A., Case, D.A., Caldwell, J.W., Ross, W.S., Cheatham, T.E., DeBolt, S., Ferguson, D., Seibel, G., Kollman, P., 1995. AMBER, a package of computer programs for applying molecular mechanics, normal mode analysis, molecular dynamics and free energy calculations to simulate the structural and energetic properties of molecules. Comput. Phys. Commun. 91, 1-41. https://doi.org/https://doi.org/10.1016/0010-4655(95)00041-D

Pettersen, E.F., Goddard, T.D., Huang, C.C., Couch, G.S., Greenblatt, D.M., Meng, E.C., Ferrin, T.E., 2004. UCSF Chimera - A visualization system for exploratory research and analysis. J. Comput. Chem. 25, 1605-1612. https://doi.org/10.1002/jcc.20084

Quimque, M.T., Notarte, K.I., Adviento, X.A., Cabunoc, M.H., de Leon, V.N., delos Reyes, F.S.L., Lugtu, E.J., Manzano, J.A., Monton, S.N., Muñoz, J.E., Ong, K.D., Pilapil IV, D.Y., Roque III, V., Tan, S.M., Lim, J.A., Macabeo, A.P., 2021a. Polyphenolic Natural Products Active In Silico against SARS-CoV-2 Spike Receptor Binding Domains and Non-Structural Proteins - A Review. Comb. Chem. High Throughput Screen. 25.

Quimque, M.T., Notarte, K.I., Letada, A., Fernandez, R.A., Pilapil, D.Y., Pueblos, K.R., Agbay, J.C., Dahse, H.-M., Wenzel-Storjohann, A., Tasdemir, D., Khan, A., Wei, D.-Q., Gose Macabeo, A.P., 2021b. Potential Cancer- and Alzheimer's Disease-Targeting Phosphodiesterase Inhibitors from Uvaria alba: Insights from In Vitro and Consensus Virtual Screening. ACS Omega 6, 8403-8417. https://doi.org/10.1021/acsomega.1c00137

Quimque, M.T.J., Notarte, K.I.R., Fernandez, R.A.T., Mendoza, M.A.O., Liman, R.A.D., Lim, J.A.K., Pilapil, L.A.E., Ong, J.K.H., Pastrana, A.M., Khan, A., Wei, D.-Q., Macabeo, A.P.G., 2021. Virtual screening-driven drug discovery of SARS-CoV2 enzyme inhibitors targeting viral attachment, replication, post-translational modification and host immunity evasion infection mechanisms. J. Biomol. Struct. Dyn. 39, 4316-4333. https://doi.org/10.1080/07391102.2020.1776639

Roe, D.R., Cheatham, T.E., 2013. PTRAJ and CPPTRAJ: Software for processing and analysis of molecular dynamics trajectory data. J. Chem. Theory Comput. 9, 3084-3095. https://doi.org/10.1021/ct400341p

Salomon-Ferrer, R., Case, D.A., Walker, R.C., 2013a. An overview of the Amber biomolecular simulation package. WIREs Comput. Mol. Sci. 3, 198-210. 
https://doi.org/https://doi.org/10.1002/wcms.1121

Salomon-Ferrer, R., Götz, A.W., Poole, D., Le Grand, S., Walker, R.C., 2013b. Routine Microsecond Molecular Dynamics Simulations with AMBER on GPUs. 2. Explicit Solvent Particle Mesh Ewald. J. Chem. Theory Comput. 9, 3878-3888. https://doi.org/10.1021/ct400314y

Santos, J., Quimque, M.T., Liman, R.A., Agbay, J.C., Macabeo, A.P.G., Corpuz, M.J.-A., Wang, Y.-M., Lu, T.-T., Lin, C.-H., Villaflores, O.B., 2021. Computational and Experimental Assessments of Magnolol as a Neuroprotective Agent and Utilization of UiO-66(Zr) as Its Drug Delivery System. ACS omega 6, 24382-24396. https://doi.org/10.1021/acsomega.1c02555

Somensi, N., Rabelo, T.K., Guimarães, A.G., Quintans-Junior, L.J., de Souza Araújo, A.A., Moreira, J.C.F., Gelain, D.P., 2019. Carvacrol suppresses LPS-induced pro-inflammatory activation in RAW 264.7 macrophages through ERK1/2 and NF-kB pathway. Int. Immunopharmacol. 75, 105743. https://doi.org/10.1016/j.intimp.2019.105743

Sun, H., Li, Y., Tian, S., Xu, L., Hou, T., 2014. Assessing the performance of MM/PBSA and MM/GBSA methods. 4. Accuracies of MM/PBSA and MM/GBSA methodologies evaluated by various simulation protocols using PDBbind data set. Phys. Chem. Chem. Phys. 16, 16719-16729. https://doi.org/10.1039/c4cp01388c

Tahir Ul Qamar, M., Ahmad, Sajjad, Khan, A., Mirza, M.U., Ahmad, Sarfraz, Abro, A., Chen, L.-L., Almatroudi, A., Wei, D.-Q., 2021. Structural probing of HapR to identify potent phytochemicals to control Vibrio cholera through integrated computational approaches. Comput. Biol. Med. 138, 104929. https://doi.org/10.1016/j.compbiomed.2021.104929

Tak, P.P., Firestein, G.S., 2001. NF-кB: A key role in inflammatory diseases. J. Clin. Invest. 107, 7-11. https://doi.org/10.1172/JCI11830

Trott, O., Olson, A.J., 2010. Software news and update AutoDock Vina: Improving the speed and accuracy of docking with a new scoring function, efficient optimization, and multithreading. J. Comput. Chem. 31, 455-461. https://doi.org/10.1002/jcc.21334

Tudla, F.A., Aguinaldo, A.M., Krohn, K., Hussain, H., Macabeo, A.P.G., 2007. Highly oxygenated cyclohexene metabolites from Uvaria rufa. Biochem. Syst. Ecol. 35, 45-47. https://doi.org/10.1016/j.bse.2006.08.006

Wang, J., Fang, X., Ge, L., Cao, F., Zhao, L., Wang, Z., Xiao, W., 2018. Antitumor, antioxidant and anti-inflammatory activities of kaempferol and its corresponding glycosides and the enzymatic preparation of kaempferol. PLoS One 13, e0197563. https://doi.org/10.1371/journal.pone.0197563

Wang, J., Wang, W., Kollman, P.A., Case, D.A., 2006. Automatic atom type and bond type perception in molecular mechanical calculations. J. Mol. Graph. Model. 25, 247-260. https://doi.org/10.1016/j.jmgm.2005.12.005

Wang, Y., Khan, A., Chandra Kaushik, A., Junaid, M., Zhang, X., Wei, D.Q., 2019. The systematic modeling studies and free energy calculations of the phenazine compounds as anti-tuberculosis agents. J. Biomol. Struct. Dyn. 37, 4051-4069. https://doi.org/10.1080/07391102.2018.1537896

Watowich, S.J., Meyer, E.S., Hagstrom, R., Josephs, R., 1988. A stable, rapidly converging conjugate gradient method for energy minimization. J. Comput. Chem. 9, 650-661. https://doi.org/https://doi.org/10.1002/jcc.540090611

World Health Organization, 2009. The Use of Herbal Medicines in Primary Health Care. Yamamoto, Y., Gaynor, R., 2005. Role of the NF-kB Pathway in the Pathogenesis of Human 
Disease States. Curr. Mol. Med. 1, 287-296. https://doi.org/10.2174/1566524013363816 